\title{
How do language-specific characteristics affect the acquisition of different relative clause types? Evidence from Finnish*
}

\author{
MINNA KIRJAVAINEN \\ University of Manchester, UK, and \\ Osaka Gakuin University, Fapan
}

EVAN KIDD

Australian National University, Australia

ARC Centre of Excellence for the Dynamics of Language

A ND

ELENA LIEVEN

University of Manchester, UK

(Received 7 October 2013-Revised I 3 May 2014-Accepted I 8 November 2015First published online II Fanuary 20I6)

\section{ABSTRACT}

We report three studies (one corpus, two experimental) that investigated the acquisition of relative clauses (RCs) in Finnish-speaking children. Study I found that Finnish children's naturalistic exposure to RCs predominantly consists of non-subject relatives (i.e. oblique, object) which typically have inanimate head nouns. Study 2 tested children's comprehension of subject, object, and two types of oblique relatives. No difference was found in the children's performance on different structures, including a lack of previously widely reported asymmetry between subject and object relatives. However, children's comprehension was modulated by animacy of the head referent. Study

[*] We would like to thank the nursery staff and children in Kotka, Finland, for their participation in the study, and the corpus child and her family for the data collection they conducted. We would also like to thank the three anonymous reviewers for their helpful comments. The study was funded by a post-doctoral research grant from the Max Planck Institute for Evolutionary Anthropology to the first author. Address for correspondence: Minna Kirjavainen, Language Education Institute, Foreign Languages Department, Osaka Gakuin University, 2-36-I Kishibe-minami, Suita-Shi, Osaka 56485 I I, Japan. e-mail: leimk@ogu.ac.jp. 
3 tested children's production of the same RC structures using sentence repetition. Again we found no subject-object asymmetry. The pattern of results suggested that distributional frequency patterns and the relative complexity of the relativizer contribute to the difficulty associated with particular RC structures.

\section{INTRODUCTION}

Cross-linguistic research is essential to theoretical development in language acquisition research, allowing us to determine universal as opposed to language-specific constraints on the acquisition process. One structure that has received considerable attention in the grammatical acquisition literature is the relative clause (henceforth RC) (see Kidd, 20II). In this paper we present three studies that investigated the acquisition of RCs in children acquiring Finnish, a language for which there is little data on RC acquisition.

\section{Acquisition of relative clauses}

Most research on the acquisition of RCs has focused on age of acquisition and the level of difficulty children experience in naturalistic and experimental contexts with subject RCs such as (I), object RCs such as (2), and oblique RCs such as (3).

(I) The dog that _ chased the cat.

(2) The cat that the dog chased

(3) The dog to whom the boy gave the bone

The general consensus amongst many scholars is that subject RCs are essentially easier to acquire than non-subject RCs, based on the following:

(a) subject RCs have been reported to emerge at an earlier developmental stage in naturalistic child language than non-subject RCs (e.g. Brandt, Diessel \& Tomasello, 2008; Diessel, 2004; Diessel \& Tomasello, 2000);

(b) the majority of experimental evidence suggests that children perform best on subject RCs in comparison to other RC types (e.g. Adani, 20I I; de Villiers, Tager Flusberg, Hakuta \& Cohen, I979; Diessel \& Tomasello, 2005; Friedmann, Belletti \& Rizzi, 2009; Goodluck, 20ı。; Guasti, Stavrakaki \& Arosio, 2012; Kas \& Lukács, 2012), although more recently some scholars have noted that this effect appears to be modulated by distributional and typological features of individual languages (Arnon, 20ıо; Brandt, Kidd, Lieven \& Tomasello, 2009; Diessel, 2009; Kidd, Brandt, Lieven \& Tomasello 2007). 
Even though there is general agreement on subject $\mathrm{RC}$ advantage over other RC types, there are several competing theoretical explanations for the effect, ranging from appeals to the primacy of subjects in syntactic derivation (either typologically: Keenan \& Comrie, I977; or formally: Rizzi, I990), appeals to processing routines and memory capacity (O’Grady, 20II), and appeals to distributional frequency (Diessel, 2004; Kidd et al., 2007). These approaches often make very similar predictions and can be difficult to distinguish. In the current paper we take a usage-based perspective, assuming that linguistic representations of structure are constructed on the basis of experience. From this perspective we consider why, for Finnish, we do not observe a clear subject advantage in $\mathrm{RC}$ acquisition.

Subject-non-subject RC asymmetry. The evidence for the subject-object asymmetry largely comes from a fairly narrow range of languages where RCs display distinct structural similarities (e.g. English, German, and Hebrew). In terms of RCs, these all are 'head-first' languages (i.e. the RC comes after the (head)noun that it modifies). Data from languages whose RCs do not display 'head-first' syntactic structure are less clear. For instance, acquisition studies with children acquiring Basque (Carreiras, Duñabeitia, Vergara, de la Cruz-Pavía \& Laka, 20ıо; Gutierrez-Mangado, 20II), Chinese (Chan, Matthews \& Yip, 20II; Chen \& Shirai, 20I4), Japanese (Ozeki \& Shirai, 2007; Suzuki, 20I I), and Quechua (Courtney, 2006) either show no difference between subject and object RCs (the most common comparison), an object RC advantage, or mixed results depending on the methodology used.

Even though data from Basque, Chinese, Japanese, and Quechua suggest that there may be no universal subject RC dominance, comparing data from these languages directly with languages like English, German, and Hebrew can be problematic for two reasons. First, Chinese, Japanese, Korean, and Basque are 'head-final' languages (i.e. the RC precedes the noun that it modifies). This means that $\mathrm{RCs}$ in these languages are structurally distinctly different from languages like English, which might explain the cross-linguistic differences in developmental and processing patterns observed between these two language groups. Second, the comparison might not be warranted because, at least for some head-final languages (e.g. East Asian languages), typologists have questioned whether true RCs actually exist (Comrie, I 998).

Finnish RCs, like English, German, and Hebrew RCs, are head-first structures. Due to the highly inflected nature of Finnish, its flexible word order, and the distributional frequencies of RCs, the acquisition of Finnish RCs is relevant to the question as to whether all head-first languages show subject dominance. 


\section{Linguistic properties of relative clauses in Finnish, and their acquisition}

Finnish is a head-first, nominative-accusative language. Prototypically, a RC directly follows its head noun. Finnish has three relative pronouns: $\mathscr{F O K}{ }^{\mathrm{r}}$ and $K U K A$, which often refer to animate entities, and $M I K \ddot{A}$, which often, but not necessarily, refers to inanimate entities (Hakulinen, Vilkuna, Korhonen, Koivisto, Heinonen \& Alho, 2005). This is similar to English speakers having the option of using that, who, or which. Unlike English, but similarly to German, Finnish relative pronouns are inflected for case and number. Relative pronouns are obligatory, and their case usually indicates what role the relativized element plays within the RCs. The nominative predominantly expresses the grammatical case of subject; the accusative, partitive, and, in some instances the genitive and nominative, express the object; genitive expresses the possessive; and the rest of the fifteen cases are locative or marginal ${ }^{2}$ (Hakulinen et al., 2005; Laaksonen \& Lieko, 2003). Indirect objects are expressed in the same way as oblique cases (i.e. by using a locative inflection on the noun). Examples (4)-(6) exemplify subject, object, and oblique RCs.

$\begin{array}{llll}\text { Kissa } & \text { mik } \ddot{\boldsymbol{a}} & \boldsymbol{l o ̈ \boldsymbol { i }} & \text { koiraa } \\ \text { Cat-NOM } & \text { which-NOM } & \text { hit-past-3sg } & \text { dog-PA }\end{array}$

\section{dog-PART}

$[\mathrm{OBJ}]$

'The cat which hit a dog'

(5)

$\begin{array}{ll}\text { Koira } & \text { mitä } \\ \text { Dog-NOM } & \text { which-PART } \\ & {[\mathrm{OBJ}]}\end{array}$

'The dog which the cat hit'

(6)

$\begin{array}{llll}\text { Sohva } & \text { miltä } & \text { koira } & \text { putosi } \\ \text { Sofa-NOM } & \text { which-ABL } & \text { dog-NOM } & \text { fall-past-3sg } \\ & {[\mathrm{LOC}]} & {[\mathrm{SUBJ}]} & \end{array}$

kissa löi

cat-NOM hit-past-3sg $[\mathrm{SUBJ}]$

$[\mathrm{OB}]$

'The sofa from/off which a dog fell'

Acquisition of relative clauses in Finnish. A small number of previous studies have touched upon Finnish RC acquisition (e.g. Kauppinen, I977; Lieko, I 992; Toivanen, I 997). However, to our knowledge there is only one past study focusing exclusively on early RC acquisition in Finnish. Kirjavainen and Lieven (20I I) reported on a naturalistic corpus analysis of one Finnish child, Piia, and her caregivers' data between the child's ages of approx. I;7 and 3;6. Piia's earliest RCs $(N=2)$ were subject $\mathrm{RCs}$, which preceded any other RC structure found in the child's data by several months. This is consistent with naturalistic data from other nominative-accusative

\footnotetext{
I Words in capital letters refer to all forms of that word.

2 'Marginal' refers to often archaic and/or unproductive cases that are infrequent in adult language and absent from children's language.
} 
languages (Brandt et al., 2008; Diessel \& Tomasello, 2000). Piia's use of RCs clauses changed when she approached her third birthday. At this point in development, oblique RCs became her most frequent RC structure (44\%), with subject and object RCs produced less frequently (each used in around $28 \%$ of all RC types). Compared to other languages this is a fairly striking result (e. g. Keenan \& Comrie, I 977). For instance, English- and German-speaking children produce oblique RCs proportionally much less frequently (English: I 4\%; Diessel and Tomasello, 2000; German: I 7\%; Brandt et al., 2008).

At least two factors can explain the discrepancy between Finnish and English/German children's use of oblique RCs. First, oblique RCs are the conventional way in Finnish to express many meanings for which Englishand German-speakers are more likely to use subject or object RCs; see examples (7) and (8).

$\begin{array}{ll}\text { Minä } & \text { rikkoin } \\ \text { I-NOM } & \text { break-I ps-past } \\ \text { oli } & \text { sinisiä raitoja } \\ \text { be-3ps-past } & \text { blue stripe-plural-PART }\end{array}$

sen kupin missä the cup-ACC which-INE be-3ps-past blue stripe-plural-PART

Corresponding English oblique RC: 'I broke the cup on which there was blue stripes'

Corresponding English subject RC: 'I broke the cup that had blue stripes (on it).'

(8) Se tyyppi

kelle me mennää tänää That person-NOM who-ALL we-NOM go-Ipl-pres today

Corresponding English oblique RC: 'The person to whom we will go today.' Corresponding English object RC: 'The person who we will go and see today.'

Consequently, oblique RCs are more frequent in Finnish children's input (42\% of RC structures; Kirjavainen \& Lieven, 20 I I) than in English (8\%; Diessel, 2004) or German (II\%; Brandt et al., 2008). This appears to result in quicker acquisition of these structures.

These distributional features of RCs in naturalistic child and caregiver Finnish would suggest that, in Finnish, oblique RCs are not more difficult than subject (or object) RCs. Thus, testing Finnish children's behaviour in experimental contexts with subject, object, and oblique RCs could shed light on the question as to whether oblique RCs are universally more difficult than subject and object RCs (e.g. Keenan \& Comrie, I977), or whether the previously observed asymmetry/hierarchy has been created by distributional properties of those structures in previously studied languages.

Second, it has been suggested that oblique RCs are more difficult than subject and object RCs because in languages such as English and German 
oblique RCs usually consist of a relative pronoun and a preposition, which either occur adjacent to each other (e.g. German: Das ist der Mann, mit dem ich getanzt habe, and English: That was the man with whom I danced) or are separated by at least two words (English: That was the man who I danced with) (Diessel \& Tomasello, 2005).3 Because in Finnish both grammatical and locative case information can be expressed by a single case-marked relative pronoun, in terms of lexical complexity, subject, object, and single-word oblique relativizers can be seen as being equally easy/ difficult. However, two types of oblique relatives occur in Finnish: one-word oblique (henceforth oblique I) RCs (see example (9)) and two-word oblique (henceforth oblique2) RCs (see example (Io)). This feature of Finnish allows us to test whether oblique RCs are inherently more difficult than subject and object RCs, or whether the reported difficulty of oblique RCs is created by the complexity of the oblique relativizer.

(9)

$\begin{array}{llll}\text { Toi on se sänky } & \text { missä } & \text { kissa } & \text { nukkui } \\ \text { That is that bed-NOM } & \text { which-INE } & \text { cat-NOM } & \text { slept } \\ \text { illalla } & & & \\ \text { evening-ADE } & & & \end{array}$

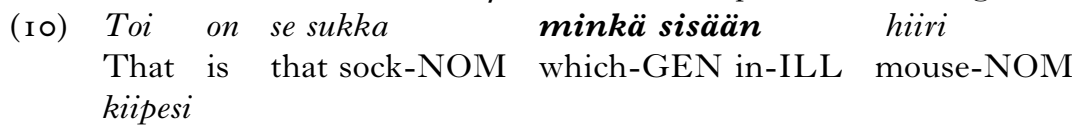

'That's the bed in which/where a cat slept in the evening'

kiipesi

climbed

'That's the sock in which a mouse climbed'

\section{The current research}

In comparison to many other head-first languages, Finnish children hear and use an overwhelmingly high number of non-subject RCs. This usage pattern, as assumed by usage-based constructivist theoretical stances (e.g. Tomasello, 2003), should have a strong influence on children's acquisition, such that Finnish-speaking children should be less likely to show a subject-advantage in comparison to children acquiring languages such as English, German, and Hebrew.

We tested these predictions across three studies. Study I reanalysed Kirjavainen and Lieven's (20II) naturalistic data, focusing on one major variable that has been shown to affect the distribution of subject and object RCs: the animacy of the head noun. Animate nouns make good

\footnotetext{
3 Note that English also has a one-word relativizer that can be used in (inanimate) oblique $\mathrm{RCs}$, where (e.g. That's the café where I proposed to my ex-wife) and a temporal relativizer when (e.g. That was the holiday when I left my wife). However, given that the research of RCs in English has heavily focused on subject and object RCs, we have relatively little information about the acquisition patterns of obliquer RCs in English.
} 
agents, whereas inanimate nouns are typically patients (Fox \& Thompson, I990). Accordingly, many studies have shown that subject RCs are more likely to have animate heads than non-subject RCs, which typically have inanimate heads (e.g. Diessel, 2009; Kidd et al., 2007). We thus asked whether this is also the case in Finnish. In Studies 2 and 3 we then investigated whether these distributional differences across different RC types significantly influence Finnish-speaking children's comprehension and production of RCs.

\section{STUDY i : CORPUS ANALYSIS}

\section{Corpus}

Piia is a monolingual first-born child in an upper-working-/middle-class family, in Kotka, southeast Finland. The language used in her corpus is colloquial speech typical to the geographical area. Piia was audio-recorded by her parents for approximately three hours per week between the ages of I;7.2 I and 4;0.I3 (approx. 270 recordings, approx. 255 hours of data in total; Kirjavainen-Max Planck corpus). The interaction during the recordings was completely spontaneous, most commonly involving an interaction between the child and one or both of her parents (or other relatives) during meal times or play sessions. After the age of 2;4 her younger sister was often present during the recordings, although she rarely took part in the interaction.

The data was transcribed using the CHAT software (MacWhinney, 2000). In the current study we include data recorded between I;7.2 I and 3;5.25 $(N=2$ io recordings, approx. 666,400 word tokens, approx. 82,300 child utterances, approx. I 57,200 adult utterances).

\section{Searches}

Morphological coding has yet to be carried out on the Piia-corpus. We therefore searched on the flo-transcription line of Piia's and her interlocutors' speech for each possible forms of different relative pronouns. The flo-line semantically mirrors the main transcription line, but represents colloquial (i.e. often shortened yet morphologically marked) word forms in standard language (see example (I I)). Our search was therefore likely to extract standard as well as colloquial relativizer forms from the data, and because the relative pronoun is an obligatory part of Finnish RC constructions, our search is likely to have extracted all RCs in the data.

( I ) Main-line: Miä juoksin siihe taloo mis oli punanen katto Flo-line: $\quad$ Minä juoksin siihen taloon missä oli punainen katto. 'I ran to the house which had a red roof' 
The KWAL program of the CLAN software (MacWhinney 2000) was used to extract sentences with relative pronouns ( $M I K \ddot{A}, \mathcal{F O K A , K U K A )}$ in fourteen cases (nominative, accusative, partitive, genitive, translative, inessive, elative, illative, adessive, ablative, allative, sublative, temporal, and causative) in the singular and plural. Cases that are unlikely to occur in relative clauses (e.g. abessive) and/or that are unlikely to be found in colloquial spoken (child) language (e.g. essive) were excluded from the search. Because some relative pronoun forms are identical to interrogative pronouns (e.g. mikä), the output was manually searched for target structures. Both restrictive and non-restrictive $\mathrm{RCs}$ were included in our analysis, and no distinction was made between the two. The child's repetitions and imitations of adults' language as well as songs and rhymes were excluded.

\section{Coding}

The search output was coded for the following:

i. the syntactic function of the NP within the RC (SUBJ, OBJ, OBL). For the purpose of this analysis, we did not distinguish between oblique $\mathrm{I}$ and oblique2 RCs because (a) Piia did not produce any oblique2 RCs in the data sampled and (b) only a handful of oblique 2 RCs (4\% of oblique RCs) were found in the adults' data.

ii. animacy of the head noun (animate, inanimate).

This was done separately for the child and her interlocutors. In Finnish, case marking on the relative pronoun often indicates the role that the relativized element plays within the RC. Because of some overlap, for instance, between subject and object pronouns, (a) the pronoun form, (b) the argument structure, and (c) semantics of the sentence were used to determine the syntactic role of the relativized NP. Toys that can be perceived as animate were coded as such. If it was impossible to determine the syntactic function or the animacy of the head, the sentence was coded as ambiguous. The coding is illustrated in Table I.

To determine reliability for the coding of the relativized element (subject, object, oblique, ambiguous), $5 \%\left(N={ }_{3} 6\right)$ of the input and $100 \%(N=39)$ of the child's targets were recoded by a second coder. The agreement was high: Child $97 \cdot 4 \%(\kappa=.924)$, Input го०\%. Disagreement in the coding for the child's targets was adjudicated by the first author.

\section{RESULTS}

We found $39 \mathrm{RC}$ structures (SUBJ: 28\%, OBJ: 28\%, OBL: 44\%) in Piia's speech and 705 (SUBJ: 29\%, OBJ: 28\%, OBL: 42\%) in her input. The small number of RCs found in Piia's data are likely due to the relatively early developmental period sampled $(1 ; 7-3 ; 6)$. Piia's data is nevertheless 
TABLE I . Examples of coding

\begin{tabular}{|c|c|c|c|}
\hline & Animate & Inanimate & Animacy ambiguous \\
\hline SUBJ & $\begin{array}{l}\text { Muistat siä sen pikku } \\
\text { prinsessan mikä eilen tuli } \\
\text { siin Pikkukakkoses? (MOT } \\
2 ; \text { I I I I }) \\
\text { Can you remember that little } \\
\text { princess that was on TV } \\
\text { yesterday? }\end{array}$ & $\begin{array}{l}\text { Kato ku se oli } \\
\text { semmonen ohjelma } \\
\text { joka tuli telkkarist } \\
\text { (MOT } 2 ; \text { I } 0 \cdot 20 \text { ) } \\
\text { See, because it was that } \\
\text { kind of a program that } \\
\text { was on TV. }\end{array}$ & $\begin{array}{l}\text { Tää mikä mulla } \\
\text { on (CHI } 2 ; \mathrm{r} \cdot 06) \\
\text { This that is at me. }\end{array}$ \\
\hline OBJ & $\begin{array}{l}\text { Otat siä sen hauvan minkä siä } \\
\text { heitit sinne? } \\
\text { (FAT } 2 ; 5 \cdot 24) \text { Can you fetch that } \\
\text { doggie that you threw there? }\end{array}$ & $\begin{array}{l}\text { Entä ne vanhat tutit } \\
\text { mitä olen käyttänyt? } \\
\text { (CHI } 3 ; 3 \cdot 2 \text { I) } \\
\text { What about the old } \\
\text { dummies that I have } \\
\text { used? }\end{array}$ & $\begin{array}{l}\text { Mikä tää oli } \\
\text { minkä siä piirsit? } \\
\text { (MOT } 1: 9 \cdot 27) \\
\text { What was this that } \\
\text { you drew? }\end{array}$ \\
\hline OBL & $\begin{array}{l}\text { Se kelle mennää tänään. } \\
\text { (CHI } 3 ; 4 \cdot \text { I } 8) \\
\frac{\text { The person }}{\text { today }} \text { to whom we'll go }\end{array}$ & $\begin{array}{l}\text { Sulla oli se punainen } \\
\text { lapio millä siä teit } \\
\text { lumitöitä. } \\
\text { (MOT 2;5.24) You had } \\
\text { that red shovel with } \\
\text { which you ploughed } \\
\text { snow. }\end{array}$ & $\begin{array}{l}\text { Se keltanen missä } \\
\text { on ne punaiset. } \\
(\text { MOT } 2 ; 5 \cdot 05) \text { The } \\
\text { yellow one in/on } \\
\text { which is the red } \\
\text { ones. }\end{array}$ \\
\hline
\end{tabular}

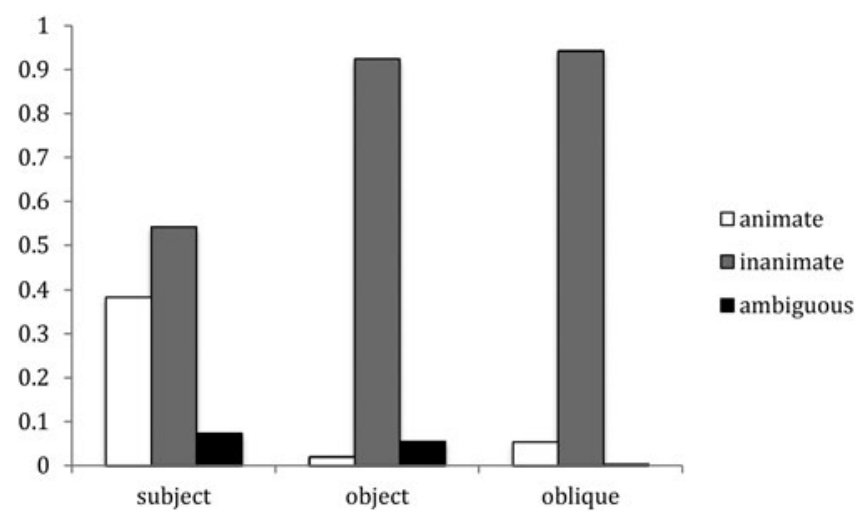

Fig. I. RC types and the animacy of head NPs in input.

included here to illustrate that the animacy of the head NP in different RC structures in her language corresponds to the pattern displayed by the Finnish adults. In four $\left(<_{\mathrm{I}} \%\right)$ of the input sentences the syntactic function of the relativized element was ambiguous and so they were excluded from the analysis. Figures I (input) and 2 (output) illustrate the proportions of animate and inanimate head referents found for each RC type.

The input and child data looked very similar. First, there were more non-subject RCs than subject RCs overall, but this was moderated by the 


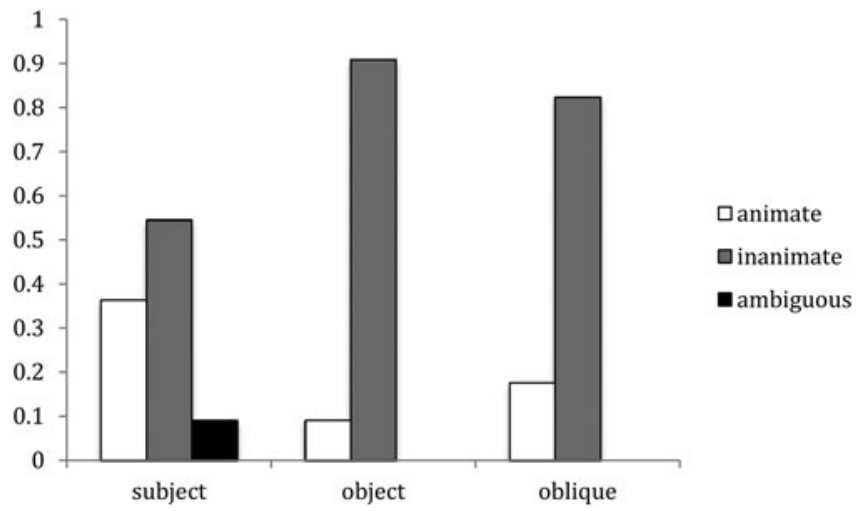

Fig. 2. RC types and the animacy of head NPs in child's speech.

animacy of the head noun. In Piia's input the distribution of animate and inanimate head nouns significantly differed across structure types (Chi-square result: $\chi^{2}=\mathrm{I}_{53} .03, \mathrm{df}=2, p<.00 \mathrm{I}, \phi=.48$ ). This significant difference was driven by the more even distribution of animate and inanimate heads in subject RCs: although when analyzed separately all structures contained significantly more inanimate than animate heads (binomial tests: subject RCs: $p=.024$, object RCs: $p<.00 \mathrm{I}$; oblique RCs: $p<. \circ \circ \mathrm{I})$, the subject $\mathrm{RC}$ result is not significant following Bonferroni adjustment $(\alpha=.05 / 3=.017)$. Indeed, removing subject $\mathrm{RCs}$ from the overall Chi-square analysis results in a non-significant result and little variance explained $\left(\chi^{2}=3 \cdot \mathrm{I}, \mathrm{df}=2, p=.08, \phi=.08\right)$, suggesting that the subject $\mathrm{RCs}$ were driving the initial significant result. Piia did not produce enough tokens of each structure type to have a good degree of confidence in any statistical analyses, and thus we merely interpret her data qualitatively.

\section{DISCUSSION}

The corpus analysis shows similar results to previous RC studies in which an effect of animacy and RC type has been found (e.g. Diessel, 2009; Fox and Thompson, I990; Kidd et al., 2007, Mak, Vonk \& Schriefers, 2002, 2006). Our Finnish-speaking child and adults rarely produce object or oblique relatives with animate heads. Consistent with Diessel (2009), subject relatives, although commonly produced with inanimate head referents, were more likely to have animate heads than the other two RC types. The close correspondence between Piia's input and her own speech suggests that children's language experience heavily shapes language use. 


\section{STUDY 2: RELATIVE CLAUSE COMPREHENSION}

The findings from Study I suggest that, (i) as in more well-studied languages, RC formation is significantly affected by the animacy of the head referent, and (ii) Finnish-speaking children hear and use considerably more non-subject than subject $\mathrm{RCs}$, a result that seems almost entirely due to the greater use of oblique RCs. In Study 2 we investigated whether these usage facts about Finnish affect children's comprehension of subject, object, and oblique I/oblique 2 RCs. In addition, by including oblique I and oblique2 RC test items, we were able to test some potential reasons for previously reported difficulty associated with oblique RCs.

Based on the assumption that animate entities make better subjects and that inanimate entities function better as objects, the usage-based prediction is that (a) children should perform better with subject than object RCs when the test sentences contain an animate head and (b) inanimate head nouns should improve performance on non-subject RCs. Furthermore, the usage-based stance assumes that distributional properties of linguistic items play an important role in affecting children's language acquisition and processing. Thus, the usage-based stance predicts that the large preponderance of non-subject RCs in Finnish children's input should affect Finnish children's representation of RCs. Specifically, the preponderance of non-subject RCs reduces the strong expectation that a relativized NP takes a subject role, such that the difference between subject and non-subject RCs observed in many other languages should be attenuated or even non-significant in Finnish. That is, no overall subject advantage is predicted for Finnish.

Three- to four-year-old children were tested on a referent selection task that measured their comprehension of subject, object, oblique I, and oblique2 RCs that contained either animate or inanimate head nouns.

\section{METHOD}

\section{Participants}

Forty children aged 3;7-4;6 were recruited from nurseries in Kotka, southeast Finland and participated in our two studies (Study 2 and Study 3). Thirty-eight of these children took part in Study 2. However, the fourteen oldest children $(4 ; 2-4 ; 6)$ were excluded from the analysis due to them being at ceiling. Thus, data from twenty-four children ( 44 female) aged $3 ; 7-4 ; \mathrm{I}$ (mean $3 ; \mathrm{IO}, \mathrm{SD}=\mathrm{I} \cdot 98$ ) were included in the current study. Apart from one child, who was tested in the home environment, the children were tested in a quiet area of their nursery. All participants were typically developing monolingual Finnish-speakers.

\section{Materials}

Thirty-two test items were created. Each of these items consisted of background sentences, one distractor sentence, and one test sentence. The 
test sentences were manipulated for the RC type (subject, object, oblique I, oblique2) and animacy of the head NP (animate, inanimate). The test sentences were nine or, in the case of the two-word relativizer sentences (oblique2), ten words long. Each background and test sentence had two NPs. Apart from a handful of test verbs (pomppia 'bounce', pomputtaa 'make something bounce', piiloutua 'hide', luikerrella 'slither', ryömiä 'crawl'), all head NPs and verbs were found in the Finnish CDI ( $16-30$ months) (Lyytinen, I999), indicating that the verbs used should be familiar to our children aged $3 ; 7-4 ; 6$. To specifically address the subjectobject asymmetry found in previous studies, half of our materials had animate heads, and were reversible (i.e. both nouns within the RC could have plausibly been the subject or object of the sentence). In addition, specifically to test animacy effects (Fox \& Thompson, i990), half of our test sentences had inanimate heads.

Finnish has an intricate case-marking system and consequently it was impossible to choose only one relativizer for our test sentences. We therefore searched for the frequencies of different relativizers in the child's output in the Kirjavainen-Max Planck corpus. Because the frequency of different relativizers in $\mathrm{RC}$ and non-RC constructions (e.g. interrogatives) varies, we were unable to tightly control for the frequency of the relativizers used between different types of target sentences. However, several instances of our subject, object, and oblique I relativizers were found in the Kirjavainen-Max Planck corpus, which we took to indicate that our experimental children were familiar with each of these relativizers. The relative pronouns in the subject $\mathrm{RCs}$ were in the nominative case, and in the object RCs in the partitive case. The relativizers used in the animate oblique RCs were kenelle (ALL) 'for whom' (oblique I) and kenen (GEN) kanssa 'with whom' (oblique2) and inanimate oblique RCs missä (INE) 'in(side) which’ (oblique I) and minkä(GEN) sisään(ILL) 'in(to) which' (oblique2). Table $\mathrm{A}$ in the 'Appendix' lists the relativizers used and their distributional frequencies.

\section{Procedure}

The children were tested in two sessions. In each session, they completed half of Study 2 materials (comprehension) and half of Study 3 materials (repetition). Half of the children were tested on Study 2 materials first, half on Study 3 materials. The order between sessions was counterbalanced so that for half of the children one set of items occurred in the first session, half in the second. For most of the children the two sessions were administered during one day so that the first session took place in the morning and the second in the afternoon. For six children the sessions took place on two consecutive days. 
The task in Study 2 was similar to the one used by Brandt et al. (2009). Presented as the 'slide-game', children were shown a small slide, and the experimenter explained that she had a lot of toys that wanted to go down the slide, but that the toys must go down one at a time. The experimenter said that she would tell the child whose turn it was to have a go, after which the child could slide the toy down.

For every target sentence, the child was shown three toys (e.g. two tigers and an elephant). The experimenter labelled the toys (e.g. "Look, I have two tigers and an elephant here"). The pair of animals (e.g. tigers) were always distinguishable by a prominent attribute (e.g. colour, size). Each of the toys then performed a different action (e.g. one tiger chased an elephant, the other tiger stroked the elephant) and was placed in front of the child. The location of the two tokens of head referent with reference to the child (i.e. left or right) was counterbalanced. Half of the correct referents for each target sentence type were placed on the right, and half on the left of the child. After the head NP toys (e.g. tigers) had been placed in front of the child, a distractor scene was acted out. For this, the additional (non-target) NP (e.g. elephant) performed an intransitive action and the experimenter explained what the toy was doing (e.g. "Look, now the elephant stomps in the jungle!"). The distractor NP was then placed between the target toys in front of the child, i.e. there were three toys (or combinations of the three toys) to choose from when the children were making their referential choices. The child was asked to give the experimenter one of the items by sliding it down the slide (e.g. "Give me the tiger that chased the elephant"). Table B in the supplementary on-line content lists the background and target sentences (see http://dx.doi.org/ıo. I 0 I $7 /$ So 3050009 I 5000768 .

\section{Coding}

The experimenter coded for the children's choices on-line as either (a) Correct (e.g. the correct tiger), (b) Head token errors (e.g. the incorrect tiger), (c) NP other errors (e.g. the elephant), (d) Other (i.e. the correct tiger with the elephant, the incorrect tiger with the elephant, both tigers selected with or without the elephant selected, or no choice was made).

\section{RESULTS}

Figure 3 reports the mean proportion correct and standard errors for each condition. Figure 3 shows that the children performed above chance $(33 \%)$ in each condition. They scored higher on sentences containing inanimate heads for all structural types except for the oblique2 structure. Additionally, they appeared to perform marginally better overall on the subject and object RCs than on the oblique RCs. 


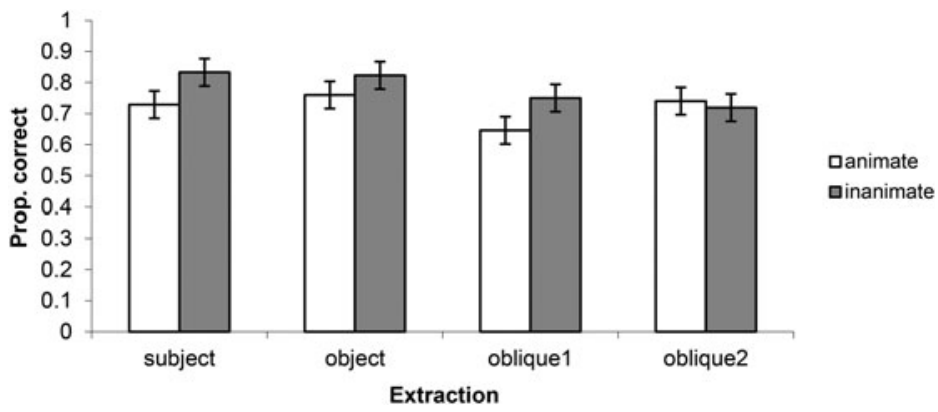

Fig. 3. Proportion correct for each test structure in Study 2. Error bars denote standard error.

The data were analyzed using Generalized Linear Mixed Models (Baayen, Davidson \& Bates, 2008; Jaeger, 2008), which were calculated using the lme 4 package for Linear Mixed Effects (Bates \& Maechler, 2010) in $R$ (version 2.I5.2; R Core Development Team, 2012). Factor labels were centred at 0 with a range of $\mathrm{I}$. An initial model that included (zero-centred) age and gender as independent variables showed that these two variables did not significantly influence performance. These variables were not included in subsequent analyses. We fitted a model to the data that included the independent variables of structure (4 levels: (i) subject RC, (ii) object RC, (iii) oblique I RC, and (iv) oblique2 RC) and animacy (2 levels: animate, inanimate), as well as participants and items as random effects. Random slope parameters for main effects and interactions were included in the models using forward selection: each random slope was added sequentially to the model, first for participants and then items, and the ANOVA function was used to determine whether the additional random slope significantly improved the model (Baayen, 2008). None of the random slopes improved the fit of the model and were therefore not included. Additionally, the structure $\times$ animacy interaction did not improve the fit of the model $\left(\chi^{2}=2 \cdot 7, \mathrm{df}=3, p=\cdot 44\right)$ and was therefore removed. The final model results are shown in Table 2 .

Table 2 shows that animacy significantly affected children's performance: across all sentence types children performed better on sentences that contained inanimate head nouns. Subject RCs were comprehended marginally better than the oblique I RCs, but the overall differences between performance on the subject RCs and the object and oblique2 RCs were not significant. Subsequent analyses revealed that the children's performance on the object RCs was significantly better overall than on the oblique I RCs $(\beta=-0.64, z=-2 . \mathrm{I}, p=.037)$ but not the oblique2 RCs $\left(\beta=-0 \cdot 44, z=-\mathrm{I} \cdot 44, p=\cdot_{15}\right)$. There was no difference in performance on the oblique $\mathrm{I}$ and oblique2 $\mathrm{RCs}(\beta=0.19, z=0 \cdot 66, p=.5 \mathrm{I})$. 
KIRJAVAINEN $E T A L$.

TAB LE 2. Final model for referential choice data in Study 2

\begin{tabular}{lrccc}
\hline & $\boldsymbol{\beta}$ & Std. error & Wald-Z & $\boldsymbol{p}$-value \\
\hline Intercept & $\mathrm{I} \cdot 44$ & $\cdot 35$ & $4 \cdot \mathrm{I} 5$ & $<\cdot 00 \mathrm{I} * * *$ \\
Structure(Obj) & $0 \cdot 08$ & $\cdot 32$ & $0 \cdot 242$ & $\cdot 8 \mathrm{I}$ \\
Structure(OBLI) & $-0 \cdot 52$ & $\cdot 30$ & $-\mathrm{I} \cdot 85$ & $\cdot 07$ \\
Structure(OBL2) & -0.37 & $\cdot 3 \mathrm{I}$ & $-\mathrm{I} \cdot 2$ & $\cdot 23$ \\
Animacy & $0 \cdot 43$ & $\cdot 22$ & $\mathrm{I} \cdot 98$ & $.048^{*}$ \\
\hline
\end{tabular}

NOTES: $* * * *<.001 ; * p<.05$; reference levels (intercept terms) for fixed-effects predictors: Structure: Subject RC, Animacy: Animate. $(\log$ likelihood $=-373 \cdot 9)$.

TABLE 3. The number of different types of errors produced by the children overall in the referential choice test

\begin{tabular}{lcccr}
\hline RC type & Head token errors & NP other errors & Other & Total \\
\hline subject-ani & I 4 & 3 & 9 & 26 \\
subject-inani & I 3 & I & 2 & I 6 \\
object-ani & I3 & 6 & 4 & 23 \\
object-inani & I I & I & 5 & I7 \\
obliqueI-ani & 24 & 2 & 8 & 34 \\
oblique -inani & I0 & 7 & 7 & 24 \\
oblique2-ani & 8 & 4 & I 3 & 25 \\
oblique2-inani & I 2 & 6 & 9 & 27 \\
Total & I05 & 30 & 57 & 192 \\
\hline
\end{tabular}

\section{Error analysis}

When children erred they most often chose the incorrect token of the head referent ( $14 \%$ of responses), although the frequency of this response did not differ across conditions. The children also sometimes chose the distractor $(4 \%)$ or made a selection that was coded as 'Other' $(7 \%)$. Table 3 lists the frequencies of these error types by condition.

\section{DISCUSSION}

The results from Study 2 suggest that, overall, three- to four-year-old Finnish-speaking children comprehend different types of RC structures very well. Based on our corpus analysis (Study I), and due to typical animacy features of subject and object entities (Fox \& Thompson, I990), we predicted that Finnish children would not show an overall subjectobject asymmetry, but that they would show animacy effects.

Consistent with our prediction, we did not find evidence of subject-object asymmetry, not even in the in the condition where the head and embedded NP were both animate (e.g. Friedmann et al., 2009; Kidd et al., 2007). Note 
also that, due to the nature of Finnish, each noun in the background sentences for each target sentence type (subject, object, oblique) was inflected (e.g. NOM, PART, INE, ALL). The main clause of each test sentence had the same structure Anna mulle se $X$ 'Give me the $\mathrm{X}-\mathrm{ACC} /$ NOM'. ${ }^{4}$ This means that the only sentence type in which the target head noun had the same case marking in the background and the target sentences were subject RCs (see examples (I 2)-(I4)).5 Furthermore, the only sentence type in which both nouns within the $\mathrm{RC}$ were inflected exactly as they were in the background sentences were animate subject RCs. If we assume that children are yet to acquire an adultlike case-marking system at the age of 3;6-4;2 (e.g. Krajewski, Lieven \& Theakston, 20I2; Krajewski, Theakson, Lieven \& Tomasello, 20I I), the mismatch in noun forms between background and target sentences may have made it more difficult for the children to process object and oblique targets, as not only did the children have to determine the meaning of the background and target sentences, they also had to pay attention to the differing forms of the key lexical item in these. Regardless of this potential extra layer of difficulty in object and oblique RCs, no subject-object asymmetry was found.

\section{(12) Tää tiikeri jahtaa norsua \\ This tiger-NOM chases elephant-PART}

'This tiger chases the elephant'

$\begin{array}{lll}\text { Tää tiikeri } & \text { paijaa } & \text { norsua } \\ \text { This tiger-NOM } & \text { strokes } & \text { elephant-PART }\end{array}$

'This tiger strokes the elephant'

Anna mulle se tiikeri kuka jahtas norsua

Give me that tiger-ACC who-NOM chased elephant-PART

'Give me the tiger who chased the elephant'

(13) Kirahvi puree tätä hiirtä

Giraffe-NOM bites this mouse-PART

'The giraffe bites this mouse'

Kirahvi pesee tätä hiirtä
Giraffe-NOM washes this mouse-PART
'The giraffe washes this mouse'

Anna mulle se hiiri mitä kirahvi puri

Give me that mouse-ACC that-PART giraffe-NOM bit

'Give me the mouse that the giraffe bit'

\footnotetext{
4 In these types of constructions, the accusative form is identical to the nominative form.

5 With reference to noun cases, our animate and inanimate materials were identical. Hence, due to lack of space, we only give examples of animate test sentences here.
} 


\section{(14) Lapsi soittaa tälle palomiehelle Child-NOM rings this fireman-ALL 'The child rings this fireman'}

$\begin{array}{lll}\text { Lapsi } & \text { irvistää } & \text { tälle palomiehelle } \\ \text { Child-NOM } & \text { grins } & \text { this fireman-ALL }\end{array}$

'The child grins at this fireman'

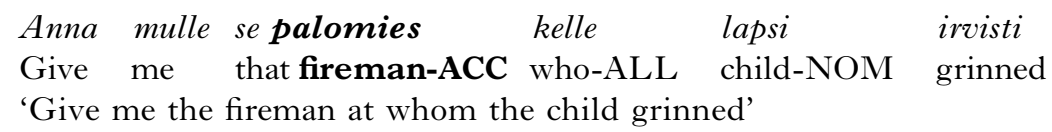

The only structure type that created a marginally increased level of difficultly were oblique I targets, which were driven by the children's relatively high error rate when choosing referents for animate oblique I targets (e.g. "Give me the cockerel for/to whom the girl read"). The children's performance in this condition may have been affected by the relative pronoun kenelle, whose frequency in adult-child conversation is relatively low in comparison to the relative pronouns in our other conditions.

The main effect of animacy showed that the children performed best when sentences contained an inanimate head, which did not interact with structure type. This result reflects our frequency analysis in Study I, but might be considered surprising with reference to the assumption that animate entities make good subjects (Fox \& Thompson, I990). That is, one might have expected better performance with animate subject than non-subject RCs.

Performance in the animate subject $\mathrm{RC}$ condition (similarly to kenelle above) may have been affected by our relative pronoun kuka. Even though this pronoun is relatively frequent in Finnish, its frequency is somewhat lower than that of our animate object relativizer. Thus, this decrement in performance may be due to experience-based phenomena.

Inconsistent with assumptions of animacy characteristics of subject and non-subject entities (Fox \& Thompson, I990), we did not find the children perform better with inanimate non-subject than subject RCs. The fact that we controlled for the noun types and used only lexical nouns across our test sentences (subject, object, oblique I, and oblique2 RCs) could explain this effect, given that several studies suggest that inanimate object relatives are easier to comprehend if the embedded subject is a pronoun than a noun (e.g. ... the dog that I stroked) (e.g. Gordon, Hendrick \& Johnson, 2001, 2004; Kidd et al., 2007; Warren \& Gibson, 2002). Thus, the fact that our test sentences consisted of embedded noun subjects (e.g. granddad instead of he) might have hindered the children's performance with inanimate non-subject RCs.

Last, we did not find oblique2 relatives to be more difficult than the other RC structures. Our Finnish comprehension data therefore do not support

$$
\text { I } 36
$$


Diessel and Tomasello's (2005) suggestion that increased structural complexity in terms of the relativizer form used results in children finding oblique2 sentences more difficult than the other RC structures (subject, object, obliquer). This finding is difficult to accommodate within the usage-based approach, since oblique2 relatives were largely absent from our corpus data. Indeed, this finding is difficult to accommodate within any current theory of RC acquisition (Keenan \& Comrie, I977; O'Grady, 2005, 20I I; Rizzi, I990). One potential explanation for the effect might be methodological. Our method tested comprehension and hence simply requires children to establish an aboutness relationship with the head referent in comparison. Even so, this result is interesting, and raises the question of whether it would be observable in production. Study 3 tested this possibility.

\section{STUDY 3: SENTENCE REPETITION}

Study 2 showed that Finnish-speaking children are influenced by the animacy of the head noun in their comprehension of RCs, but that, unlike children acquiring many other languages, they do not show a subject RC advantage. This result is important because it can potentially help shed light on psycholinguistic processes that take place during $\mathrm{RC}$ acquisition. However, null effects are difficult to interpret; thus there is a need to follow up Study 2 using a different method. Study 3 did so using sentence repetition. The method is a particularly sensitive measure of children's grammatical knowledge (Lust, Flynn \& Foley, I996), and has been shown to both be sensitive to and predict children's knowledge of different RC structures (Boyle, Lindell \& Kidd, 2013; Diessel \& Tomasello, 2005; Kidd et al., 2007). As Study 2 raised some questions in relation to animacy effects, in Study 3 we conducted a detailed error analysis to investigate the source of errors in different RC types.

\section{METHOD}

\section{Participants}

The forty children described in our Study 2 also took part in the current study. Of these, three children (I female, 2 male) were tested but were not cooperative and testing was discontinued. Thus, thirty-seven $(\mathrm{N}=37,22$ female) children aged $3 ; 7-4 ; 6($ Mean $=4 ; 0, \mathrm{SD}=3.8)$ were included in the study.

\section{Materials}

Thirty-two test sentences and fourteen fillers were created. The test sentences were manipulated for the RC type (subject, object, oblique I, 
oblique2) and animacy of the head NP (animate, inanimate). The sentences were controlled for length ( I 4-I 5 syllables long). Because we assumed that the shorter colloquial word forms would be easier for the children than the longer more formal variants, the sentences were created in colloquial dialect typical for the area where the children lived (e.g. tossa was used for tuossa 'there', kelle for kenelle 'for whom', kenen kaa for kenen kanssa 'with whom'). The fillers were short simple sentences such as Ulkona sataa 'It's raining outside'. Table $\mathrm{C}$ in the supplementary on-line content lists the test and filler sentences (see http://dx.doi.org/ı o. Io I 7/So3050009 I 5000768.

\section{Familiarity of items to children}

Nouns. We carefully selected the head NPs and nouns within the relative clauses in the test sentences. All of these were lexical nouns, and all are listed in the Finnish MacArthur CDI (I6-30 months) (Lyytinen, I999), which we took to mean that they should be familiar to Finnish children aged $3 ; 7-4 ; 6$. A selection of data files of the Kirjavainen-Max Planck Finnish child corpus was searched for the frequency of these nouns between the ages of I;7 and 4;0 (approx. I 55,000 word tokens produced by the child at the time of the searches). The head nouns were selected so that they had relatively similar frequencies in the child's speech. See Table D in the 'Appendix' for the relative frequencies of head nouns used in our study. Because of the limited number of nouns that children can be assumed to be familiar with (Lyytinen, I999), and that appeared with similar frequencies in the naturalistic speech of our Finnish corpus child, and because we needed both head and RC nouns, some nouns were used in more than one test sentence. Whenever possible, these sentences were presented to the children in separate test sessions. The fact that we manipulated for head noun animacy (animate vs. inanimate), limited ourselves to familiar nouns with similar frequencies, and did not want to repeat the same nouns several times during the test session, also meant that many of our test sentences were not reversible, or were biased towards one interpretation.

Relativizers. The same relativizers were used as in Study 2.

Verbs. Due to the limited number of verbs young children know, and because only a relatively small number of verbs can be easily represented pictorially (as required by our method), it was impossible to control for test sentence verb frequency. However, we set a criterion for our test verbs whereby each verb type (i) had to be listed in the Finnish MacArthur CDI ( I6-30 months) (Lyytinen, I999), and (ii) appear at least once in our Finnish corpus child's speech. Highly frequent verbs (such as 'go') were excluded. Therefore, our test verbs should be familiar to children aged between 3;7 and 4;6, but there should not be huge differences in the verb 
frequency overall. Apart from three verbs (halata 'to hug', leikkiä 'to play', siivota 'to clean/tidy up'), all verbs appeared in only one test sentence. These three verbs were each used in two test sentences, which were presented in different test sessions and occurred in different sentence types.

The main clauses were always predicate nominal of copular clauses (e.g. 'That is $\mathrm{X}(\mathrm{NOM})$ ').

\section{Procedure}

A PowerPoint slideshow was created in which each test sentence was paired up with a picture of the head referent. A native Finnish speaker (the first author) prerecorded the test sentences using Audacity software. Four different orders were created of the PowerPoint slideshows and children were randomly assigned to one order.

The test was presented to the children as a 'parrot-game'. The children were told that they would see pictures on the computer screen and that they would have to pretend that they are parrots and say the same thing as the computer.

Prior to beginning the experiment, the children completed six practice trials, which presented six simple sentences. The first practice sentence (e.g. Siinä on nostokurki 'That is a crane') was repeated by the experimenter to demonstrate what was required of the child. The second sentence was then played back to the child and s/he was asked to repeat it (e.g. Siinä on palapeli 'That is a jigsaw puzzle'). To motivate the children in the task, when the child repeated (or attempted to repeat) the sentence, they were given a sticker to put on a colourful drawing. If the child did not produce a verbatim repetition of the warm-up sentence, the experimenter reminded the child that they were pretending to be a parrot and had to say exactly the same thing as the computer. If the child did not repeat the sentence, the experimenter played the sentence back to the child again and asked the child to repeat it. Once all warm-up sentences had been repeated in this manner the experimenter proceeded to the actual test items.

If during testing the child did not produce a response after hearing the test sentence, the sentence was played back once more and the experimenter encouraged the child to try to repeat the sentence. If the child did not attempt to repeat the sentence, the experimenter moved to the next item. If the child did not attempt to repeat five consecutive sentences, the testing was discontinued and the child excluded from the study.

The materials were counterbalanced as per the description in our Study 2.

The test situations were audio-recorded. The experimenter transcribed the children's responses on-line and checked the transcriptions against the recordings off-line. Data from one session of eight children ( I0.8\% of data) were transcribed and coded for reliabilities by a native Finnish speaker RA. Inter-coder agreement was very good $(94.53 \%, \kappa=\cdot 917)$. 


\section{Coding}

Each repetition attempt was coded for using a similar coding scheme as Diessel and Tomasello (2005). The child's final attempt was taken as the response, i.e. children were given credit for self-correction (e.g. 'That is the pig that ... with whom the sheep ran outside').

The children were given a score of $\mathrm{I}$ if they produced a verbatim repetition of the test sentence. Minor errors were overlooked (and were coded as I). These included:

- The child changed the relativizer to a different one but with the same function (e.g. joka-NOM for $k u k a-N O M)$. This is comparable to an English-speaking child changing, e.g. which for that/who or vice versa.

- The use of colloquial or standard language form of a given word (e.g. kelle vs. kenelle 'for whom').

- Change in the position of the adverbial within the RC. Because Finnish has a flexible word order, changing the place of an adverbial does not justify penalization.

- Change of the adverbial to a different one (e.g. 'yesterday' for 'a moment ago').

- Addition of an extra adverbial (e.g. 'That's the boy who helped Granddad in the forest yesterday' for 'That's the boy who helped Granddad in the forest').

- Minor changes to the main-clause demonstrative (e.g. 'That is the boy ...' for 'There is the boy ...').

- Exclusion of a definite marker in the main clause, e.g. Toi on poika ... for Toi on SE poika ... ('That is boy ...' for 'That is THAT boy ...'). This decision was made because definiteness is not very clear or systematic in Finnish.

- When the child made minor changes to NPs within the RC or the head referent (e.g. 'a boy' for 'a child').

A score o was given:

- When there was no attempt at repetition.

- When the child did not produce a RC structure, e.g. the child produced a simple or coordinate sentence.

- When the child changed the relativizer to one with a different function (e.g. kelle-ALL 'for whom' for kuka-NOM 'who').

- Distinctly incorrect word order within the RC clause (e.g. Possu minkä lammas kaa juoksi 'A pig whom a sheep with ran' for Possu minkä/kenen kaa lammas juoksi 'A pig with whom a sheep ran').

- When the utterance had a resumptive pronoun.

- Errors other than minor lexical errors (e.g. the use of a different verb, omitting nouns, verbs, or relativizers). 


\begin{tabular}{|c|c|}
\hline Response type & Example \\
\hline $\begin{array}{l}\text { Verbatim or near verbatim } \\
\text { repetition }\end{array}$ & - \\
\hline No response/No RC produced & - \\
\hline $\begin{array}{l}\text { Wrong relativizer with the same } \\
\text { function as the target }\end{array}$ & jota-OBJ for mitä-OBJ \\
\hline $\begin{array}{l}\text { Wrong relativizer with a different } \\
\text { function as the target }\end{array}$ & mitä-OBJ for mikä-SUBJ \\
\hline Omission of the relativizer & $\begin{array}{l}\text { Tossa on se hassu vauva (kelle) setä nauroi 'That's the } \\
\text { funny baby (at whom) a man laughed' }\end{array}$ \\
\hline Resumptive (pro)noun was used & $\begin{array}{l}\text { Tossa on se laiva mikä laiva työnsi jäätä 'That's the boat } \\
\text { that the boat pushed ice' }\end{array}$ \\
\hline Major lexical errors & Non-target verb used within the RC \\
\hline Word order errors & $\begin{array}{l}\text { Toi on se ankka kenen kukko kaa äsken leikki 'That's the } \\
\text { duck whom the cockerel with played a moment ago' }\end{array}$ \\
\hline $\begin{array}{l}\text { A number of errors produced } \\
\text { within a given response }\end{array}$ & $\begin{array}{l}\text { Tossa on se tyttö kuka luki usein kirjaa for Tossa on se } \\
\text { tyttö kenelle mummo luki usein 'That's the girl who } \\
\text { often read a book' for 'That's the girl to whom a granny } \\
\text { read often' }\end{array}$ \\
\hline
\end{tabular}

In addition to coding the responses as incorrect (O) or correct (I), we also coded the responses into nine more detailed categories to assess the types of errors that the children made. It is important to note that some errors that we coded in the binary error analysis as correct responses were coded as errors in this more detailed analysis. For instance, repetitions in which the child produced a non-target relativizer whose case was nevertheless the same as the target relativizer's (e.g. joka-NOM for kuka-NOM) were coded as correct in our binary analysis but as errors in our detailed error analysis. Table 4 illustrates the error categories for our detailed error analysis.

\section{RESULTS}

Figure 4 reports the mean proportion correct and standard errors for each condition. Figure 4 shows that the children performed best on subject and object RCs. Animacy had an uneven effect on performance across the test structures: inanimate heads only resulted in better performance for object and oblique I RCs, whereas the opposite was the case for the subject and oblique2 relatives.

The data were analyzed using Generalized Linear Mixed Models (Baayen, Davidson \& Bates, 2008; Jaeger, 2008), which were calculated using the lme 4 package for Linear Mixed Effects (Bates \& Maechler, 2010) in $R$ (version 2.15.2; R Core Development Team, 2012). Factor labels were centred at o with a range of $\mathrm{I}$. An initial model that included (zero-centred) age and gender as independent variables showed that these two variables did not 


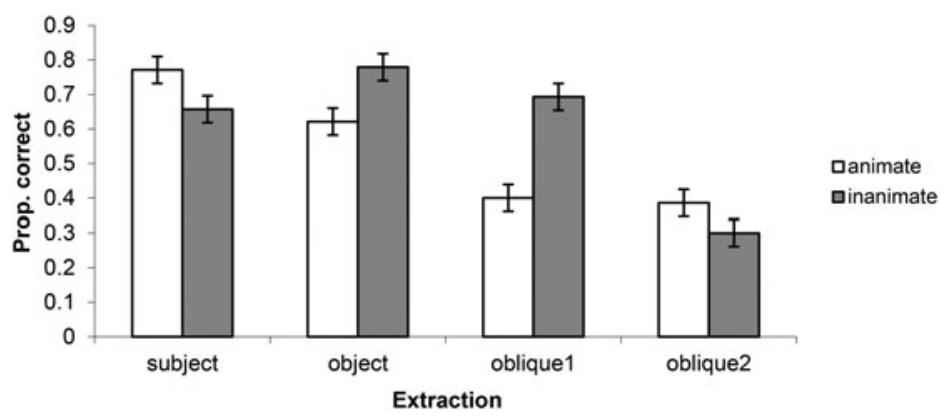

Fig. 4. Proportion correct for each test structure in Study 3. Error bars denote standard error.

TABLE 5. Final model of elicited imitation data in Study 3

\begin{tabular}{|c|c|c|c|c|}
\hline & $\beta$ & Std. error & Wald-Z & $p$-value \\
\hline Intercept & $\mathrm{I} \cdot 5$ & .29 & $5 \cdot 14$ & $<.00 \mathrm{I} * * * *$ \\
\hline Structure(Obj) & -0.91 & $\cdot 49$ & $-\mathrm{I} \cdot 87$ & .06 I \\
\hline Structure(OBLI) & $-2 \cdot 14$ & $\cdot 48$ & $-4 \cdot 46$ & $<\cdot 00$ I*** \\
\hline Structure(OBL2) & $-2 \cdot 18$ & $\cdot 45$ & $-4 \cdot 8_{5}$ & $<.00 \mathrm{I} * * *$ \\
\hline Animacy & $-0.7 \mathrm{I}$ & $\cdot 40$ & $-\mathrm{I} \cdot 79$ & .07 \\
\hline Structure(Obj):Animacy & $\mathrm{I} \cdot 67$ & .56 & $2 \cdot 97$ & $<\cdot 0 I^{*} * *$ \\
\hline Structure(OBLI):Animacy & $2 \cdot 43$ & $\cdot 56$ & $4 \cdot 3 \mathrm{I}$ & $<.00$ I $* * *$ \\
\hline Structure(OBL2):Animacy & 0.16 & $\cdot 56$ & 0.29 & $\cdot 77$ \\
\hline
\end{tabular}

NOTES: $* * * p<.00 \mathrm{I} ; * * p<.0 \mathrm{I} ; * p<.05$. Reference levels (intercept terms) for fixed-effects predictors: Structure: Subject RC, Animacy: Animate.

significantly influence performance. These variables were not included in subsequent analyses. We fitted a model to the data that included the independent variables of structure (4 levels: (i) subject RC, (ii) object RC, (iii) oblique I RC, and (iv) oblique2 RC) and animacy (2 levels: animate, inanimate), as well as participants and items as random effects. Random slope parameters for main effects and interactions were included in the models using forward selection: each random slope was added sequentially to the model, first for participants and then items, and the ANOVA function was used to determine whether the additional random slope significantly improved the model (Baayen, 2008). The final model only included the by-participants random slope for the fixed variable of structure. The final model results are shown in Table 5 .

Table 5 shows that, whereas the children did not differ in their overall performance on subject and object RCs, the subject RCs were more often repeated correctly than were both categories of oblique RCs. Subsequent analyses revealed that the children's performance on the object RCs was 
also significantly better overall than on both the Oblique- $\mathrm{I} \operatorname{RCs}(\beta=-\mathbf{I} \cdot 23$, $z=3.0 \mathrm{I}, p=.003)$ and Oblique $-2 \operatorname{RCs}(\beta=-\mathrm{I} \cdot 28, z=-2.8 \mathrm{I}, p=.005)$, but that their overall performance on the two Oblique categories did not differ $(\beta=-0.05, z=-0.12, p=.92)$. The main effect of animacy was marginal; a series of structure $\times$ animacy interactions suggested animacy affected performance depending on the structural type.

The structure $\times$ animacy interactions were explored further by splitting the data by animacy. The same analysis strategy as per the previous analysis was employed. The sentences containing animate head nouns were analyzed first. The random slope for items did not significantly contribute to the model and was therefore not included in the final model; the random effects of participants and items and the random slope for participants were included. The results showed that the difference in children's performance on subject and object RCs was marginal and not significant $(\beta=-0 \cdot 90, z=-\mathrm{r} \cdot 76$, $p=.08$ ). In contrast, performance on the subject RCs with animate heads was significantly higher than on the Oblique $(\beta=-2 \cdot 06, z=-4 \cdot 22, p<\cdot .0$ I $)$ and Oblique 2 RCs $(\beta=-2 \cdot 22, z=-4 \cdot 37, p<\cdot 00 \mathrm{I})$. Subsequent analyses revealed that the children's performance on object $\mathrm{RCs}$ with animate heads was significantly better than their performance on both Oblique I RCs with animate heads $\left(\beta=-\mathrm{I}_{\mathrm{I}} \mathrm{I}_{5}, z=-2 \cdot 55, p=\cdot 0 \mathrm{II}\right)$ and Oblique2 $\mathrm{RCs}(\beta=-\mathrm{I} \cdot 32$, $z=-2 \cdot 62, p=\cdot 009)$, which did not differ from each other $(\beta=-0 \cdot 17, z=-$ $0 \cdot 36, p=\cdot 72)$.

We next analyzed children's performance on sentences that contained inanimate head nouns. The random effect and the random slope for items were not significant and were therefore not included in the model; the random effect and the random slope for participants were included. The results showed that children performed significantly better on object RCs with an inanimate head than with both subject $\mathrm{RCs}\left(\beta=-0 \cdot 78, z=-2 \cdot \mathrm{I}_{3}\right.$, $p=.033)$ and oblique2 $\mathrm{RCs}(\beta=-3 \cdot 2, z=-5 \cdot 46, p<.00 \mathrm{I})$, but not oblique I $\operatorname{RCs}(\beta=-0 \cdot 39, z=-\mathrm{I} \cdot 23, p=\cdot 22)$. The difference between performance on subject and oblique I RCs with inanimate heads was not significant $(\beta=0.39$, $z=0.97, p=.33)$, but performance on both of these sentence types was significantly higher than performance on oblique2 RCs (subject RCs: $\beta=-2 \cdot 4, z=-4.75, p<.00 \mathrm{I}$; oblique I RCs: $\beta=-2 \cdot 78, z=-4 \cdot 92, p<.00 \mathrm{I})$.

Finally, we analyszed whether animacy of the head referent affected performance on each individual structure type. Children performed significantly better on subject RCs with an animate head than with an inanimate head $(\beta=-0.79, z=-2 \cdot \mathrm{I}, p=.04)$. In contrast, they performed better on object and oblique I RCs with inanimate heads than with animate heads (object RCs: $\beta=0.99, z=2 \cdot 42, p=.02$; Oblique $\mathrm{I}: \beta={ }_{\mathrm{I}} \cdot 77$, $z=3.33, p<.001)$. Finally, the children performed marginally better on Oblique2 RCs with animate heads than with inanimate heads, but the effect was not significant $(\beta=-\mathrm{I} \cdot 04, z=-\mathrm{I} \cdot 79, p=\cdot 07)$. 


\section{Detailed error analysis}

In addition to our statistical analysis above, we conducted a descriptive error analysis separately for each RC type. Recall that not all repetitions coded as errors in our detailed error analyses were coded as such in our statistical analyses above. Hence, the proportions of errors below do not directly correspond to the proportions of errors reported above.

Subject gapped relatives. The children produced (near) verbatim repetitions of animate subject $\mathrm{RCs} 36 \%(\mathrm{~N}=50 / 140)$ of the time. For inanimate subject $\mathrm{RCs}$ the proportion was $5 \mathrm{I} \% \quad(\mathrm{~N}=7 \mathrm{I} / \mathrm{I} 40)$. When producing non-verbatim repetitions, the children most commonly changed the target for a non-target relativizer that had the same function (i.e. same case) as the target. This is comparable to an English speaker producing which for that. These types of responses were not coded as errors in our statistical analysis but were coded as errors here. Repetitions like these were particularly prevalent in animate subject $\mathrm{RCs}(4 \mathrm{I} \%[\mathrm{~N}=58 / \mathrm{I} 40])$. Instead of producing the target relativizer, $k u k a-\mathrm{NOM}$, the children produced an alternative relativizer correctly in the nominative case (mikä [57\%], joka [43\%]). Fifteen percent $(\mathrm{N}=2 \mathrm{I} / \mathrm{I} 40)$ of inanimate subject $\mathrm{RC}$ repetitions were instantiations of these (joka-NOM [57\%], kuka-NOM [43\%] for $m i k \ddot{a}-\mathrm{NOM})$.

The children also commonly changed the case of the subject relativizer (animate: I0\%, $\mathrm{N}=14 / 140$; inanimate: I $9 \%, \mathrm{~N}=27 / 140$ ) and hence created grammatically deviant sentences. These errors are comparable to an English speaker producing whom instead of who. In both animate and inanimate subject $\mathrm{RCs}$ the target relativizers were most commonly replaced with mitä-PART (animate: $64 \%$, inanimate: $70 \%$ ) or jota-PART (animate: $29 \%$, inanimate: $15 \%$ ). The partitive case is used for the object function, and hence in these contexts the use of the partitive results in deviant sentences with two object and no subject referents. Note, however, that structurally most of these sentences look like subject RCs as illustrated by ( I 5). That is, our participants rarely changed the location or the case of the other NPs within the RCs to reflect the needs of the incorrectly case-marked relative pronoun. Because the children only changed the case of the relativizer, it is likely that they understood the grammatical roles for each participant, but for one reason or another failed to inflect the relativizer correctly. Thus, we do not take these types of repetitions as object-for-subject conversions. On the other hand, three animate and four inanimate object-for-subject conversions were found. In these, the relative pronoun was produced incorrectly in the partitive (object) case, the target object referent was produced incorrectly in the nominative case and it preceded the verb, as shown in ( 16 ).

$\begin{array}{lllll}\text { (1 5) } & \text { Toi on se poika } & \text { mitä } & \text { auttoi pappaa } \\ \text { That is the boy that-PART } & \text { helped granddad-PART }\end{array}$


metsäss $\ddot{a}$

forest-INE

'That is the boy *whom helped granddad/old man in the forest'

For the target sentence:

Toi on se poika kuka auttoi pappaa

That is the boy who-NOM helped granddad-PART

metsässä

forest-INE

'That is the boy who helped granddad/old man in the forest'

(г6) Toi on se poika mitä pappa

That is the boy that-PART granddad-NOM

auttoi metsässä

help-3sg-past forest-INE

'That is the boy whom granddad/old man helped in the forest'

Object gapped relatives. Fifty-five percent $(\mathrm{N}=77 / \mathrm{I} 40)$ of animate object RC responses were (near) verbatim repetitions. In inanimate object $\mathrm{RCs}$ these accounted for $7 \mathrm{I} \%(\mathrm{~N}=\mathrm{I} 00 / \mathrm{I} 40)$ of responses. The error type the children most commonly produced when repeating animate $(20 \%, \mathrm{~N}=$ 28/140) and inanimate ( $1 \%, N=$ I6/140) object targets were repetitions in which the target relativizer was replaced with a relativizer with a different function, i.e. the children produced grammatically deviant sentences. In these, the children most commonly (animate: $N=25 / 28$; inanimate: $\mathrm{N}=\mathrm{I} 4 / \mathrm{I} 6$ ) changed the object relativizer (mitä-PART) into a subject relativizer (mikä-NOM, joka-NOM, $k u k a-\mathrm{NOM})$. Five animate and one inanimate subject-for-object RC conversions were found in which the target object $\mathrm{RC}$ was converted incorrectly into a subject $\mathrm{RC}$ by using a nominative marking on the relative pronoun, moving the $\mathrm{RC}$ subject referent in the canonical object position (following the verb), and inflecting the subject referent for the object (partitive) case; see example ( I 7 ).

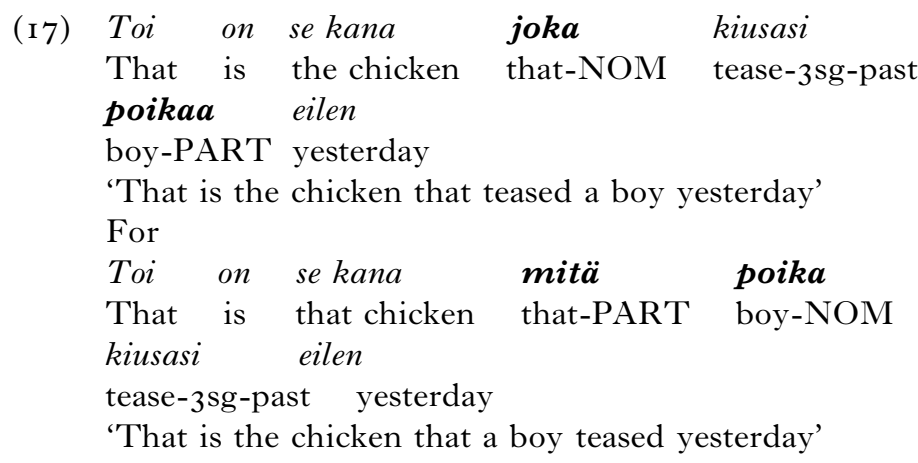


One-word oblique relatives. The children struggled to repeat animate oblique I relatives - they produced (near) verbatim repetitions only $26 \%$ $(\mathrm{N}=36 / 140)$ of the time. A further $14 \%(\mathrm{~N}=20 / \mathrm{I} 40)$ of the responses contained a correctly inflected, non-target relativizer, (joka-ALL (70\%), mikä-ALL $(3 \circ \%)$ for kuka-ALL). Thirty-one percent of repetitions were such that the children changed the relativizer to one with a different function. Most commonly they produced nominative or partitive forms instead of the target allative form (kuka-NOM $(26 \%) j o k a-\mathrm{NOM}(2 \mathrm{I} \%)$, mik $\ddot{a}$-NOM (I $4 \%$ ), jota-PART ( $2 \%$ ), mitä-PART ( $9 \%)$ ). The children also frequently produced repetitions of animate oblique I RCs which had more than one error $(21 \%, N=29 / 140)$.

Contrary to animate oblique I RCs, the children performed very well with inanimate oblique I relatives, producing (near) verbatim responses $64 \%(\mathrm{~N}=$ $90 / \mathrm{I} 40$ ) of the time. A further $6 \%$ of their responses were repetitions in which the target relativizer was replaced with another correctly inflected relativizer. That is, the children's repetition accuracy was much better with inanimate than animate oblique I RCs regardless of whether we consider producing a correctly inflected non-target relativizer as an error or not. The most common error type with inanimate oblique $\mathrm{RC}$ was the use of a relativizer with a different function to the target relativizer $(2 \mathrm{I} \%, \mathrm{~N}=29$ / I 40, of oblique I RC responses). There was no clear pattern in these, but the most common erroneous relativizers used were mitä-PART $(27 \%)$, joka-NOM ( $17 \%)$, and jota-PART (1०\%), such as is exemplified by (I8):

$\begin{array}{lllll}\text { Toi on se sänky } & \text { mitä } & \text { kissa } & \text { nukkui } \\ \text { That is that bed } & \text { that-PART } & \text { cat-NOM } & \text { slept } \\ \text { illalla } & & & & \end{array}$

in the evening

'*That is the bed that a cat slept in the evening'

For

Toi on se sänky missä kissa nukkui

That is that bed that-INE cat-NOM slept

illalla

in the evening

'That is the bed in which a cat slept in the evening'

Two-word oblique relatives. The children performed badly with animate and inanimate two-word oblique relatives. They produced (near) verbatim repetitions of these only $26 \%(\mathrm{~N}=27 / \mathrm{I} 40$; animate $)$ and $2 \mathrm{I} \%(\mathrm{~N}=20 / \mathrm{I} 40$; inanimate) of their responses. A further $7 \%$ and $2 \%$ of the repetitions, respectively, had a correctly inflected non-target two-word relativizer replacing the target relativizer, e.g. minkä +kaa 'with whom' for kenen + kaa 'with whom'. 
The error pattern for the two-word oblique relatives was relatively clear. The children most commonly produced errors in which they replaced the two-word relativizer with a one-word relativizer (animate: $35 \%, \mathrm{~N}=8 \mathrm{I}$ / I40; inanimate: $58 \%, \mathrm{~N}=4 \mathrm{I} / \mathrm{I} 40$ ). The incorrect single word relativizers produced in repetitions of inanimate oblique2 $\mathrm{RCs}$ had similar semantics as the two-word target relativizer. Instead of producing minkä sisään 'into which', the children commonly produced mihin 'which-ILL' ('into which'), minne 'which-SUBL' ('into which'), or missä 'which-INE' ('in which'). However, the responses for animate oblique2 targets very rarely resembled the target either semantically or structurally. These responses were overwhelmingly such that the children replaced the relativizer with a semantically unacceptable one (subject or object case), or produced repetitions with a number of errors; see example (19).

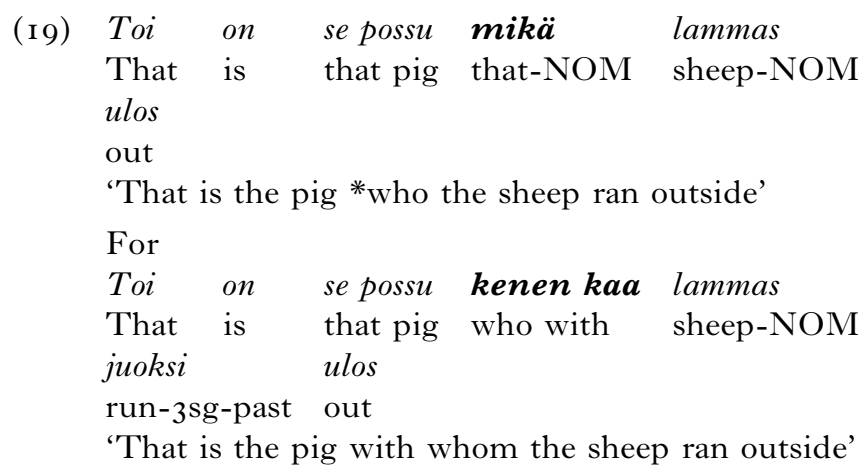

\section{DISCUSSION}

Several results from Study 3 bear on theoretical issues relevant to RC acquisition. First, we did not find an across the board significant subject $\mathrm{RC}$ advantage when test sentences contained animate or inanimate head nouns. In particular, the difference between subject and object RCs was not significant. Furthermore, unlike some previous studies (e.g. Diessel \& Tomasello, 2005) which report that children relatively frequently convert object RCs into subject RCs (e.g. That's the cat that bit the dog for That's the cat that the dog bit) we only found a handful of subject-for-object conversions $(\mathrm{N}=6 / 280$ of which 5 heads were animate, I inanimate), and an equal number $(\mathrm{N}=7 / 280,3$ animate, 4 inanimate) of object-for-subject conversions. Relative pronoun case errors were also equally prevalent in both directions. Eighty-eight percent $(\mathrm{N}=36 / 4 \mathrm{I}$ of which animate: I3/I4, inanimate: 23/27) of the subject relativizer case errors were such that the partitive (object) was produced instead of the nominative, whereas $89 \%$ $(\mathrm{N}=39 / 44$ of which animate: $25 / 28$, inanimate $14 / 16)$ of the object 
relativizer case errors were such that the nominative (subject) was produced instead of the partitive. This result, even though not completely comparable to the materials (namely, reversibility) or method (comprehension vs. repetition) of some previous studies (e.g. Friedmann et al., 2009), points towards the possibility that no universal subject dominance exists in RC acquisition.

Second, the children's performance on the subject, object, and oblique I RCs is broadly consistent with the distributional properties of Finnish found in Study I. In particular, object and oblique I RCs were best repeated when they contained inanimate heads. In contrast, subject RCs were best repeated when they contained animate heads. Although subject RCs in Study I were most often produced with inanimate heads, there are several reasons to suggest that the children's performance is consistent with usage patterns. First, animate nouns are typically agents. This is likely to have contributed to children's better performance on animate in comparison to inanimate subject RCs. Second, the animacy effect for subject RCs was influenced by our coding scheme. If only verbatim repetitions are counted, the children performed better on the inanimate subject RCs. The animate subject RC advantage only emerged when we allowed grammatically correct relative pronoun substitution to count as a correct repetition.

Third, our results differ from some previous studies that have found oblique RCs difficult for children (e.g. Brandt et al., 2008; Diessel \& Tomasello, 2000, 2005; Rahmany, Marefat \& Kidd, 20I I). Our results do not support the suggestion that oblique RCs are more difficult than object RCs because object RCs are semantically similar to simple transitives while oblique RCs are not (Diessel, 2009). The semantic dissimilarity between these two structures is present in Finnish yet certain oblique RCs were as easy for our Finnish children as object RCs. Diessel and Tomasello (2005) suggested that oblique RCs are difficult in English and German because the relativizer in these constructions consists of two words and the other RC types consist of just one. The fact that we found that our Finnish children perform worse with oblique2 than (inanimate) oblique I RCs could be taken as support for Diessel and Tomasello's suggestion. Many (animate: 35\%; inanimate: $58 \%$ ) oblique2 repetitions were such that the children erroneously replaced the two-word relativizer with a one-word relativizer. In almost all repetitions in which the child substituted the inanimate two-word relativizer (minkä sisään 'into which'), they did so by producing a semantically similar one-word relativizer (mihin-ILL 'into which', minne-SUBL 'into which', miss $\ddot{a}-\mathrm{INE}$ 'in which'). This created a semantically sound, but incorrectly repeated, RC structure, indicating that they understood the meaning of the target sentence but struggled to repeat it. There is no one-word relativizer in 
Finnish the semantics of which correspond to our animate oblique2 relativizer. Regardless of this, $35 \%$ of the children's animate oblique 2 responses were such that the child replaced the target with a one-word relativizer (commonly nominative or partitive forms). This finding is similar to Diessel and Tomasello's (2005) study, which found that English and German children also erroneously replaced two-word with one-word relativizers.

\section{GENERAL DISCUSSION}

We conducted three studies investigating the acquisition of relative clauses in Finnish-speaking children. Study $\mathrm{I}$ analyzed the naturalistic productions of one Finnish-speaking child and her caregivers. In comparison to other languages for which there is comparable data, we found that Finnish contains a comparatively higher proportion of non-subject RCs. We also found that RCs are most typically used with inanimate head nouns. In Study 2 we conducted a comprehension experiment and found that, in contrast to other head-first languages (e.g. English, German, Hebrew), there does not appear to be a subject-object asymmetry in Finnish. Instead of structure, consistent with the usage patterns observed in Study I, children's comprehension was most affected by the animacy of the head referent. Finally, in Study 3 we conducted a sentence repetition study, the results of which revealed a good degree of consistency with Studies I and 2.

\section{No subject-object asymmetry}

Let us first consider the fact that we found no difference between subject and object RCs. This is cross-linguistically an unexpected result, given that studies investigating RC acquisition in many other head-first languages have reported strong subject RC dominance (Adani, 20II; de Villiers et al., I979; Diessel \& Tomasello, 2005; Friedmann, et al., 2009; Goodluck, 20ıо; Guasti, et al., 2012; Kas \& Lukács, 2012).

Consistent with the predictions of the usage-based approach to language acquisition, the lack of subject-object asymmetry in our study can be explained by the children's behaviour in our experiments heavily reflecting distributional features of Finnish. For instance, in German, subject RCs are much more frequent than object or oblique RCs in the input (Brandt et al., 2008), contributing to the subject advantage observed in German. However, in English (Diessel, 2004) and Finnish children's input, subject and object RCs are roughly equally frequent. This means that, all things being equal, Finnish and English children's performance with subject and object RCs might be predicted to be similar, yet it is only in Finnish where the subject advantage is not present. 
Importantly, not all things are equal between these two languages. First, the much greater proportion of non-subject than subject RCs in Finnish, relative to English, means that the expectations Finnish speakers have about the head noun is less strongly skewed in favour of subject function than it is for English speakers.

Second, English has a relatively rigid word order. The strong agent/actor + Verb schema of simple sentences in English has been argued to affect expectations of sentence-/clause-initial nouns, contributing to the subjectobject asymmetry (e.g. Diessel \& Tomasello, 2005; Slobin and Bever, I 982). Finnish having a more flexible word order than English means that Finnish speakers may not have as strong a preference for placing agents/ actors in sentence-/clause-initial positions as English speakers.

Third, in Finnish it is usually the relative pronoun that ultimately determines the participant roles within the relative clause. Thus, the relativized syntactic role is often reliably disambiguated as soon as the relativizer is heard. In languages such as English, in which identical relative pronoun forms are used for subject and object RCs, speakers/ hearers are more likely to be garden-pathed than in Finnish.

Given that we found no subject-object asymmetry, it may be worth briefly discussing our age range and its implications. Our experimental studies included children from a relatively narrow age range $(3 ; 7-4 ; 6)$. Thus, even though we did not find a subject-object asymmetry, this asymmetry might be found in younger or older age groups. Let us address the younger children first. Without experimental evidence it is difficult to determine whether very young Finnish children $(<3 ; 7)$ would show a subject advantage. However, our corpus study, which extracted RCs between the ages of $2 ; 6$ and $3 ; 6$, found that, in terms of frequency of use, no preference for using subject RCs was present in the child's language. If a Finnish child does not show a preference for subject over non-subject RCs in naturalistic situations, it is likely that they do not show a preference for using them in experimental situations either, and consequently make subject for non-subject RC errors, for instance. Furthermore, our corpus analysis showed that the corpus child's input contained fewer exemplars of subject relatives than non-subject relatives. Based on a large body of first language research which shows that children's language is significantly influenced by the language input they hear (e.g. Cameron-Faulkner, Lieven \& Theakston, 2007; Huttenlocher, Vasilyeva, Cymerman \& Levine, 200I; Kidd, Lieven \& Tomasello, 2006; Kirjavainen, Theakston \& Lieven, 2009; Rowland, 2007), it is not likely that Finnish children would go through a stage during which they show subject dominance, in particular if at the age of $3 ; 7-4 ; 6$ they do not show it.

The second possibility is that subject advantage arises after the upper limit of our age range $\left(>_{4} ; 6\right)$. Two facts suggest this is not the case. First, our 
corpus analysis did not find subject RCs to be more prevalent in the adults' language, i.e. Finnish adults do not prefer to use subject RCs over object/ oblique RCs, at least not when they are interacting with children. Even though it is not impossible, it is improbable that, while Finnish speakers do not show a subject advantage before $4 ; 6$ or in adulthood, they go through a period somewhere in between when subject-object asymmetry is present. Second, if a subject RC advantage arose after a developmental stage during which children are already extremely competent in comprehending and producing subject and object RCs (as they were in our Study 2 and Study 3), the emerged subject preference would not tell us much about the processes that take place in language acquisition but about something else.

\section{Oblique relatives}

We next turn to oblique relatives. Our study provided little support for Diessel's (2009) suggestion that semantic dissimilarity between oblique RCs and transitive sentences results in children's poorer performance with oblique than object RCs. On the other hand, our data support Diessel and Tomasello (2005) and suggest that it is the two-word relativizer that contributes to the difficulty associated with oblique structures in languages such as English and German. The fact that in our Study 2 the children comprehended oblique 2 relatives as well as they did subject, object, and oblique r relatives indicates that the children's poor performance with oblique2 relatives in the sentence repetition task did not derive from the children not understanding who is doing what to whom, but the production of the more complex sentence structure relative to the other structures created the difficulty. It seems that, if oblique relatives and their relativizers are structurally similar to subject and object relatives, no apparent difficulty is associated with oblique relatives. Future experimental research investigating children's performance with oblique I and oblique2 $\mathrm{RCs}$ in other languages would help to assess the role of relativizer complexity in the difficulty associated with oblique RCs.

There are some other factors that are likely to affect children's performance with oblique RCs. First, if a speaker has two or more constructions to choose from to express similar meanings (e.g. oblique I vs. oblique2), these constructions might compete for production, and the stronger variant is selected (e.g. Bates \& MacWhinney, i987, I989). Factors such as frequency, complexity, and semantic predictability can be assumed to contribute to the strength of a given variant. The finding (Study 3) that our children commonly replaced the two-word relativizers with one-word relativizers can be taken as support for this suggestion. Second, when producing oblique2 RCs, children have to engage in 
inflection and sequencing within the sentence of two relativizer words. This is likely to put more pressure on the processing system - in particular during production - relative to relative clauses with a one-word relativizer. Third, most two-word relativizers (in English, German, and Finnish) are much less frequently represented in naturalistic interaction than one-word relativizers, which is likely to contribute to speakers' proficiency with oblique 2 and oblique I constructions, in the favour of the latter.

Two results did not reflect our corpus analysis and hence require some consideration. First, we found that oblique relatives were the most frequent $(42 \%) \mathrm{RC}$ type in our corpus analysis, but our children did not perform better with oblique than subject/object relatives in our experiments. In fact, they performed worse with animate oblique I and animate and inanimate oblique 2 RCs in our Study 2. At face value, this could be taken as evidence against the usage-based account. However, the usage-based account does not assume a complete input-output mirroring. Even though language-specific distributional features are expected to mould children's language, other factors also contribute to patterns of acquisition. Such factors include (a) the degree with which a construction resembles other constructions the child already knows (e.g. Abbot-Smith \& Behrens, 2006; Diessel \& Tomasello, 2005) and (b) speakers' ability to memorize chunks of varying lengths and combine these to create longer and more complex utterances (e.g. Ellis, 2003; Pine \& Lieven, I997). Furthermore, it is not only the frequency of the syntactic constructions that affects the acquisition, but the frequency of key lexical items within those constructions, and in other (related or unrelated) constructions. The fact that our animate oblique r relativizer and animate and inanimate obliquez relativizers occur in Finnish naturalistic language less frequently than our other relativizers is likely to explain at least partly why the children found these sentence types difficult. Furthermore, the usage-based account does not assume that children acquire the oblique (or any other) relative clause structure as one single category, but that initially different locative cases are learned one by one. This means that the acquisition trajectory of one instantiation of a construction (e.g. oblique I with the relativizer missä) could be acquired more quickly than another instantiation of that same syntactic construction (e.g. oblique I with the relativizer kenelle). Last, our corpus analysis found only a handful of oblique2 relatives in the input (and none in the corpus child's output). Consequently, the usage-based account would predict that oblique2 RCs are more difficult and learned later in development than many subject, object, and oblique I RCs.

Second, we found that both animate object and animate oblique I RCs were infrequent in our corpus analysis. If we assume that usage patterns have a major effect on children's language development, both of these 
sentence types should be difficult for children in experimental contexts. However, the children performed significantly better with animate object than animate oblique I RCs. One might suggest that animate objects make bad head referents for oblique RCs, resulting in a poor performance with those items, but there is no clear perceptual reason to assume that locative cases would be incompatible with animate heads, in particular since our children found animate oblique2 RC easier than inanimate oblique2 RCs. However, some locative cases may be perceptually more compatible with animate than inanimate head referents and vice versa. For instance, the inessive case (in $X$ ) could be more likely to occur with inanimate heads (e.g. 'the cup in which' vs. 'the man in whom').

An alternative reason for the animate object-oblique asymmetry is differences in lexical frequencies of the relativizers. Even though Finnish children are not likely to experience the animate object relativizer used in our test sentences in animate object constructions frequently, they do relatively frequently experience it as a relativizer in inanimate object RCs and as a question word in interrogative constructions. On the other hand, the animate obliqueI relativizer is infrequent in animate oblique I structures, as well as in other constructions. We suggest that the fact that the children were more familiar with the animate object than oblique I relativizer resulted in children having a sound understanding of the meaning of the former lexical item, which helped them to comprehend and produce RCs with that relativizer.

\section{Conclusion}

Our results suggest that (a) the frequency of a given RC construction as well as the frequency of a given relativizer within RC (and, importantly, also in non-RC) constructions contributes to children's proficiency of different RC structures, and (b) the syntactic function of the relativized element alone does not determine the difficulty associated with comprehending and repeating those structures. It seems to be that, in Finnish, subject, object, and oblique $\mathrm{RCs}$ are more or less equally easy/difficult to comprehend and produce, but that the difficulty associated with some structures seems to be created largely by the syntactic/lexical frequency and the complexity of the relativizer.

SUPPLEMENTARY MATERIALS

For supplementary material for this paper, please visit http://dx.doi.org/ıo. I $017 /$ So3050009 I 5000768 .

\section{REFERENCES}

Abbot-Smith, K. \& Behrens, H. (2006). How known constructions influence the acquisition of other constructions: the German passive and future constructions. Cognitive Science 3o, 995-I026. 
Adani, F. (20II). Rethinking the acquisition of relative clauses in Italian: towards a grammatically based account. Fournal of Child Language 38, I4I-65.

Arnon, I. (2010). Rethinking child difficulty: the effect of NP type on children's processing of relative clauses in Hebrew. Fournal of Child Language 37, 27-5 I.

Baayen, H. (2008). Analyzing linguistic data: a practical introduction to statistics using $R$. Cambridge: Cambridge University Press.

Baayen, R. H., Davidson, D. J. \& Bates, D. M. (2008). Mixed-effects modeling with crossed random effects for subjects and items. Fournal of Memory and Language 59, 390-4I2.

Bates, E. \& MacWhinney, B. (1987). Competition, variation, and language learning. In B. MacWhinney (ed.), Mechanisms of language acquisition, I57-93. Hillsdale, NJ: Lawrence Erlbaum.

Bates, E. \& MacWhinney, B. (I989). Functionalism and the competition model. In B. MacWhinney \& E. Bates (eds), The crosslinguistic study of sentence processing, 3-76. Cambridge: Cambridge University Press.

Bates, D. M. \& Maechler, M. (2010). lme4: linear mixed-effects models using $\mathrm{S}_{4}$ classes. R package version 999375-33, online: <http://lme4.r-forge.r-project.org>.

Boyle, W., Lindell., A. K. \& Kidd, E. (2013). Investigating the role of verbal working memory in young children's sentence comprehension. Language Learning 63, 2 I I-42.

Brandt, S., Diessel, H. \& Tomasello, M. (2008). Acquisition of German relative clauses: a case study. Fournal of Child Language 35, 325-48.

Brandt, S., Kidd, E., Lieven, E. \& Tomasello, M. (2009). The discourse bases of relativization: an investigation of young German- and English-speaking children's comprehension of relative clauses. Cognitive Linguistics 20, 539-70.

Cameron-Faulkner, T., Lieven, E. V. M. \& Theakston, A. L. (2007). What part of no do children not understand? A usage-based account of multiword negation. Fournal of Child Language 34, $25 \mathrm{I}-82$.

Carreiras, M., Duñabeitia, J. A., Vergara, M., de la Cruz-Pavía, I. \& Laka, I. (2010). Subject relative clauses are not universally easier to process: evidence from Basque. Cognition II5, 79-92.

Chan, A., Matthews, S. \& Yip, V. (201 I). The acquisition of relative clauses in Cantonese and Mandarin. In E. Kidd (ed.), Acquisition of relative clauses: processing, typology, and function, 197-226. Amsterdam: John Benjamins.

Chen, J. \& Shirai, Y. (20I4). The acquisition of relative clauses in spontaneous child speech in Mandarin Chinese. Fournal of Child Language 20, I-29.

Comrie, B. (1998). Rethinking the typology of relative clauses. Language Design I, 59-86.

Courtney, E. H. (2006). Adult and child production of Quechua relative clauses. First Language 26, 317-38.

de Villiers, J. G., Tager Flusberg, H. B., Hakuta, K. \& Cohen, M. (I979). Children's comprehension of relative clauses. Fournal of Psycholinguistic Research 8, 499-5 I8.

Diessel, H. (2004). The acquisition of complex sentences. Cambridge: Cambridge University Press.

Diessel, H. (2009). On the role of frequency and similarity in the acquisition of subject and non-subject relative clauses. In T. Givón \& M. Shibatani (eds), Syntactic complexity, 25 I-76. Amsterdam: John Benjamins.

Diessel, H. \& Tomasello, M. (2000). The development of relative clauses in spontaneous child speech. Cognitive Linguistics $\mathbf{I}(\mathrm{I} / 2), \mathrm{I}_{3} \mathrm{I}-5 \mathrm{I}$.

Diessel, H. \& Tomasello, M. (2005). A new look at the acquisition of relative clauses. Language 81, 882-906.

Ellis, N. C. (2003). Constructions, chunking, and connectionism: the emergence of second language structure. In C. Doughty \& M. H. Long (eds), Handbook of second language acquisition, 33-68. Oxford: Blackwell.

Fox, B. A. \& Thompson, S. A. (I990). A discourse explanation of the grammar of relative clauses in English conversation. Language 66, 297-3 I6.

Friedmann, N., Belletti, A. \& Rizzi, L. (2009). Relativized relatives: types of intervention in the acquisition of A-bar dependencies. Lingua I 19, 67-88. 
Goodluck, H. (2010). Object extraction is not suitable to Child Relativized Minimality. Lingua I20, I 5 I 6-2 I.

Gordon, P. C., Hendrick, R. \& Johnson, M. (200I). Memory interference during language processing. Fournal of Experimental Psychology: Learning, Memory, and Cognition 27, I 4 II -23 .

Gordon, P. C., Hendrick, R. \& Johnson, M. (2004). Effects of noun phrase type on sentence complexity. Fournal of Memory and Language 5I, 97-I I 4.

Guasti, M. T., Stavrakaki, S. \& Arosio, F. (2012). Crosslinguistic differences and similarities in the acquisition of relative clauses: evidence from Greek and Italian. Lingua 122, 700-1 3.

Gutierrez-Mangado, M. J. (20 I I). Children's comprehension of relative clauses in an ergative language: the case of Basque. Language Acquisition 18, I76-201.

Hakulinen, A., Vilkuna, M., Korhonen, R., Koivisto, V., Heinonen, T. R. \& Alho, I. (2005). Iso suomen kielioppi [The large grammar of Finnish]. Helsinki: Suomalaisen Kirjallisuuden Seura.

Huttenlocher, J., Vasilyeva, M., Cymerman, E. \& Levine., S. (200I). Language input and child syntax. Cognitive Psychology 45, 337-74.

Jaeger, T. F. (2008). Categorical data analysis: away from ANOVAs (transformation of not) and towards logit mixed models. Fournal of Memory and Language 59, 434-46.

Kas, B. \& Lukács, Á. (2012). Processing relative clauses by Hungarian typically developing children. Language and Cognitive Processes 27, 500-38.

Kauppinen, A. (I 977). Mikon kielioppia: 3 vuoden 4 kuukauden ikäisen pojan kielestä ja sen kehittymisestä vuoden aikana [Mikko's grammar: one 3 year and 4 month old boy's language and its development over a one year period]. Unpublished licentiate thesis, University of Helsinki, Department of Finnish Language.

Keenan, E. \& Comrie, B. ( I 977). Noun phrase accessibility and universal grammar. Linguistic Inquiry 8, 63-99.

Kidd, E. (ed.) (201 I). The acquisition of relative clauses: processing, typology, and function. Amsterdam: John Benjamins.

Kidd, E., Brandt, S., Lieven, E. \& Tomasello, M. (2007). Object relatives made easy: a cross-linguistic comparison of the constraints influencing young children's processing of relative clauses. Language and Cognitive Processes 22, 860-97.

Kidd, E., Lieven, E. V. M. \& Tomasello, M. (2006). Examining the role of lexical frequency in the acquisition and processing of sentential complements. Cognitive Development 2r, 93-107.

Kirjavainen, M. \& Lieven, E. (201 I). The acquisition of relative clauses in Finnish; the effect of input. In E. Kidd (ed.), Acquisition of relative clauses: processing, typology, and function, I07-39. Amsterdam: John Benjamins.

Kirjavainen, M., Theakston, A. \& Lieven, E. (2009). Can input explain children's me-for-I errors? Fournal of Child Language 36, I09 I-I I4.

Krajewski, G., Lieven, E. V. M. \& Theakston, A. L. (2012). Productivity of a Polish child's inflectional noun morphology: a naturalistic study. Morphology 22, 9-34.

Krajewski, G., Theakston, A. L., Lieven, E. V. M. \& Tomasello, M. (201 I). How Polish children switch from one case to another when using novel nouns: challenges for models of inflectional morphology. Language and Cognitive Processes 26, 830-6r.

Laaksonen, K. \& Lieko, A. (2003). Suomen kielen äänne- ja muoto-oppi [Finnish language phonology and morphology]. Helsinki: Oy Finn Lectura Ab.

Lieko, A. (1992). The development of complex sentences: a case study of Finnish. Helsinki: Suomalaisen Kirjallisuuden Seura.

Lust, B., Flynn, S. \& Foley, C. (I996). What children know about what they say: elicited imitation as a research method for assessing children's syntax. In D. McDaniel, C. McKee \& H. Smith Cairns (eds), Methods for assessing children's syntax, 55-77. London: MIT Press.

Lyytinen, P. (I 999). Varhaisen kommunikaation ja kielenkehityksen arviointimenetelmä [Early communication and language development assessment method]. Jyväskylä: Niilo Mäki Instituutti \& Jyväskylän Yliopiston Lapsitutimuskeskus. 
MacWhinney, B. (2000). The CHILDES project. Hillsdale, NJ: Erlbaum.

Mak, W. M., Vonk, W. \& Schriefers, H. (2002). The influence of animacy on relative clause processing. Fournal of Memory and Language 47, 50-68.

Mak, M. M., Vonk, W. \& Schriefers, H. (2006). Animacy in processing relative clauses: the hikers that rocks crush. Journal of Memory and Languagem 54, 466-49o.

O'Grady, W. (2005). Syntactic carpentry: an emergentist approach to syntax. Mahwah, NJ: Erlbaum.

O'Grady, W. (20II). Relative clauses: processing and acquisition. In E. Kidd (ed.), Acquisition of relative clauses: processing, typology, and function, I3-38. Amsterdam: John Benjamins.

Ozeki, H. \& Shirai, Y. (2007). The consequences of variation in the acquisition of relative clauses: an analysis of longitudinal production data from five Japanese children. In Y. Matsumoto, D. Oshima, O. Robinson \& P. Sells (eds), Diversity in language: perspectives and implications, 243-70. Stanford, CA: CSLI Publications.

Pine, J. \& Lieven, E. (1997). Slot and frame patterns and the development of the determiner category. Applied Psycholinguistics 18, I 23-38.

R Core Development Team (2012). R: A language and environment for statistical computing. R Foundation for Statistical Computing, Vienna, Austria. ISBN 3-90005 I-07-0, online: $<$ http://www.R-project.org/>.

Rahmany, R., Marefat, H. \& Kidd, E. (20II). Persian-speaking children's acquisition of relative clauses. European Fournal of Developmental Psychology 8, $367-88$.

Rizzi, L. (1990). Relativized minimality. Cambridge, MA: MIT Press.

Rowland, C. (2007). Explaining errors in children's questions. Cognition 104 106-34.

Slobin, D. I. \& Bever., T. G. (I982). A crosslinguistic study of word order and inflections. Cognition 12, 229-65.

Suzuki, T. (20II). A case-marking cue for filler-gap dependencies in children's relative clauses in Japanese. Fournal of Child Language 38, I084-95.

Toivanen, J. (I 997). The acquisition of Finnish. In D. Slobin (ed.), The crosslinguistic study of language acquisition, vol. 4, 87-182. Mahwah, NJ: Lawrence Erlbaum Associates Inc. Publishers.

Tomasello, M. (2003). Constructing a language; a usage-based theory of language acquisition. London: Harvard University Press.

Warren, T. \& Gibson, E. (2002). The influence of referential processing on sentence complexity. Cognition 85, 79-1 I 2 .

\section{APPENDIX}

Table B.

Please see http://dx.doi.org/ı. Iо 17/So3050009 5000768.

TABle C.

Please see http://dx.doi.org/Io. Ior 7/So3050009 5000768. 
TABLE A. Frequencies of the relative pronouns in our corpus child's data that were used in our experimental materials

\begin{tabular}{|c|c|c|c|c|c|}
\hline Pronoun & Function & Animacy & $\begin{array}{l}\text { Overall } \\
\text { freq }\end{array}$ & $\begin{array}{l}\% \text { of all word } \\
\text { tokens }\end{array}$ & $\begin{array}{l}\% \text { of all } \\
\text { relativizer use }\end{array}$ \\
\hline kuka & SUBJ & animate & 452 & $0.30 \%$ & $3 \%$ \\
\hline mikä & SUBJ & inanimate & 643 & $0.40 \%$ & $21 \%$ \\
\hline mitä & $\mathrm{OBJ}$ & animate & I 443 & $0.90 \%$ & $21 \%$ \\
\hline mitä & $\mathrm{OBJ}$ & inanimate & I 443 & $0.90 \%$ & $21 \%$ \\
\hline kenelle & $\mathrm{OBL}_{\mathrm{I}}$ & animate & IO & $<0.01 \%$ & $3 \%$ \\
\hline missä & $\mathrm{OBL}_{\mathrm{I}}$ & inanimate & 1058 & $0.70 \%$ & $33 \%$ \\
\hline $\begin{array}{l}\text { kenen } \\
\text { kanssa }\end{array}$ & $\mathrm{OBL}_{2}$ & animate & 0 & $0.00 \%$ & ०\% \\
\hline $\begin{array}{c}\text { minkä } \\
\text { sisään }\end{array}$ & $\mathrm{OBL}_{2}$ & inanimate & $\circ$ & $0.00 \%$ & ०\% \\
\hline
\end{tabular}

TABLE D. The frequency of head nouns used in Study 3 relative to all word tokens in the Kirjavainen-Max Planck corpus

\begin{tabular}{|c|c|c|c|}
\hline & Noun & Gloss & Frequency \\
\hline \multirow[t]{4}{*}{ SUBJ-ani } & Täti & Lady & 0.00019 \\
\hline & Setä & Man & 0.00014 \\
\hline & Poika & Boy & 0.00034 \\
\hline & Mummo & Granny & 0.00012 \\
\hline \multirow[t]{4}{*}{ SUBJ-inani } & Laiva & Ship & 0.00028 \\
\hline & Kynä & Pen & 0.00039 \\
\hline & Mehu & Juice & 0.00070 \\
\hline & Auto & Car & $0.0006_{3}$ \\
\hline \multirow[t]{4}{*}{ OBJ-ani } & Kana & Chicken & 0.00003 \\
\hline & Lintu & Bird & 0.00023 \\
\hline & Koira & Dog & 0.00035 \\
\hline & Pupu & Rabbit & 0.00044 \\
\hline \multirow[t]{4}{*}{ OBJ-inani } & Kakku & Cake & 0.00030 \\
\hline & Auto & Car & 0.00063 \\
\hline & Ruoka & Food & 0.00013 \\
\hline & Talo & House & 0.00023 \\
\hline \multirow[t]{4}{*}{ OBLI-ani } & Tyttö & Girl & 0.00040 \\
\hline & Lapsi & Child & 0.00035 \\
\hline & Pappa & Granddad & 0.00070 \\
\hline & Vauva & Baby & 0.00240 \\
\hline \multirow[t]{4}{*}{ OBLI-inani } & Talo & House & 0.00023 \\
\hline & Kauppa & Shop & 0.00035 \\
\hline & Sänky & Bed & 0.00012 \\
\hline & Kuppi & Cup & 0.00025 \\
\hline \multirow[t]{4}{*}{ OBL2-ani } & Kissa & Cat & 0.00050 \\
\hline & Pöllö & Owl & 0.00019 \\
\hline & Possu & Pig & ०.०००I 6 \\
\hline & Ankka & Duck & 0.00035 \\
\hline \multirow[t]{4}{*}{ OBL2-inani } & Paita & Shirt & 0.00035 \\
\hline & Sukka & Sock & $0.0002 \mathrm{I}$ \\
\hline & Kauppa & Shop & 0.00035 \\
\hline & Kaappi & Cupboard & 0.00009 \\
\hline
\end{tabular}

